\title{
Article \\ OsMre11 Is Required for Mitosis during Rice Growth and Development
}

\author{
Miaomiao Shen, Yanshen Nie, Yueyue Chen, Xiufeng Zhang and Jie Zhao* \\ State Key Laboratory of Hybrid Rice, College of Life Sciences, Wuhan University, Wuhan 430072, China; \\ shenmm@whu.edu.cn (M.S.); nie_ys@whu.edu.cn (Y.N.); 2011202040109@whu.edu.cn (Y.C.); \\ zhang1994@whu.edu.cn (X.Z.) \\ * Correspondence: jzhao@whu.edu.cn
}

Citation: Shen, M.; Nie, Y.; Chen, Y.; Zhang, X.; Zhao, J. OsMre11 Is Required for Mitosis during Rice Growth and Development. Int. J. Mol. Sci. 2021, 22, 169. https://doi.org/ 10.3390/ijms22010169

Received: 1 December 2020

Accepted: 22 December 2020

Published: 26 December 2020

Publisher's Note: MDPI stays neutral with regard to jurisdictional claims in published maps and institutional affiliations.

Copyright: (c) 2020 by the authors. Licensee MDPI, Basel, Switzerland. This article is an open access article distributed under the terms and conditions of the Creative Commons Attribution (CC BY) license (https: / / creativecommons.org/ licenses/by/4.0/).

\begin{abstract}
Meiotic recombination 11 (Mre11) is a relatively conserved nuclease in various species. Mre11 plays important roles in meiosis and DNA damage repair in yeast, humans and Arabidopsis, but little research has been done on mitotic DNA replication and repair in rice. Here, it was found that Mre11 was an extensively expressed gene among the various tissues and organs of rice, and lossof-function of Mre11 resulted in severe defects of vegetative and reproductive growth, including dwarf plants, abnormally developed male and female gametes, and completely abortive seeds. The decreased number of cells in the apical meristem and the appearance of chromosomal fragments and bridges during the mitotic cell cycle in rice mre11 mutant roots revealed an essential role of OsMre11. Further research showed that DNA replication was suppressed, and a large number of DNA strand breaks occurred during the mitotic cell cycle of rice mre11 mutants. The expression of OsMre11 was up-regulated with the treatment of hydroxyurea and methyl methanesulfonate. Moreover, OsMre11 could form a complex with OsRad50 and OsNbs1, and they might function together in non-homologous end joining and homologous recombination repair pathways. These results indicated that OsMre11 plays vital roles in DNA replication and damage repair of the mitotic cell cycle, which ensure the development and fertility of rice by maintaining genome stability.
\end{abstract}

Keywords: OsMre11; mitotic cell cycle; DNA replication; DNA damage repair; root apical meristem

\section{Introduction}

DNA replication in the cell cycle and cell division is vital to the development and reproduction of all organisms. Complete and accurate DNA replication not only maintains the stability of the genome but also is important for accurate transmission of DNA genetic information to daughter cells. The replicon hypothesis related to DNA replication originated in the 1960s and was used to explain the control of initiation of bacterial replication [1]. In E. coli, DNA replication is controlled by the starting gene oriC. After the initiation of replication, hemimethylated oriC can be generated, and other proteins can bind to it and prevent the assembly of new replication initiation complexes [1,2]. In eukaryotes, DNA replication begins in the $S$ phase of the cell cycle [3]. When the recognition complex binds to an initiation site, replication begins. The proteins CDC6 (cell division cycle 6) and CDT1 (chromatin license and DNA replication factor 1) participate together in DNA replication initiation, and MCM (recruit minichromosome maintenance) complex facilitates DNA replication [3,4]. When DNA replication is wrong or blocked, certain proteins are involved in repairing the defective DNA, and then, the replication event continues. However, when the loss-of-function occurs in factors related to DNA replication, it may cause a large number of genomic instability and affect the normal growth and development of organisms [5].

Organisms in nature are often affected by endogenous and exogenous factors, resulting in DNA double-strand breaks (DSBs). Endogenous DNA damage is often generated in the process of DNA replication and transposon excision, while exogenous DNA damage 
tends to be induced by ionizing radiation, biochemical reagents, ultraviolet irradiation, and so on [6]. DSBs are highly toxic lesions that can cause chromosomal translocations and rearrangements that ultimately lead to senescence, cell death, or tumorigenesis [7]. Therefore, maintaining genome integrity is vital for precise inheritance of genes and cell survival.

Once DSBs are produced, specific proteins are recruited to repair them. There are two major DSB repair pathways, non-homologous end joining (NHEJ) and homologous recombination (HR) [8,9]. NHEJ is the main pathway of DSB repair and runs through the entire life cycle. In this pathway, the two ends of the broken DNA can connect together quickly and directly using little or no homologous sequence, resulting in genetic mutation or chromosomal aberration. HR is a more accurate repair pathway compared with NHEJ. In this pathway, the broken DNA end uses sister chromatin or a homologous sequence as a template to synthesize new DNA, which only works in the S and G2 phases of the cell cycle [10].

Meiotic recombination 11 (Mre11), radiation sensitive 50 (Rad50), and Nijmegen breakage syndrome 1 (Nbs1) (or X-ray sensitive 2 [Xrs2] in Saccharomyces cerevisiae) form the MRN (or MRX) complex. In the presence of damage, MRN is the first sensor responding to DSBs and is critical for recruiting other repair proteins and activating ATM (Ataxia telangiectasia mutated) and ATR (ATM and Rad3 related) kinases [11-13]. Mre11 and Rad50 are highly conserved in biological evolution, while Nbs1/Xrs2 is less conserved and only found in eukaryotes [14]. The MRN complex can recognize DSB ends. Once it binds to DNA molecules, the DNA unwinds to facilitate the successful repair [15]. The gene Mre11 encodes a nuclease protein that was first identified by screening in yeast. Mre11 is the critical protein in the MRN complex and digests the DNA by its $3^{\prime}$ to $5^{\prime}$ exonuclease activity and $5^{\prime}$ to $3^{\prime}$ endonuclease activity $[16,17]$. Rad50 is an ATPase and has two long coiled-coil domains, acting as an intermediate bridge to connect the broken DNA end [18]. Nbs1 is an important component in determining the location of DNA damage, controlling the activity of the MRN complex, detecting DNA damage signaling, and recruiting ATM to DSB ends [19-21].

In the S phase and G2 phase of the cell cycle, Mre11 cleaves the $5^{\prime}$-strand of the DNA DSB ends to produce a single-stranded DNA gap through its endonuclease activity $[22,23]$. During this process, the NHEJ pathway is prevented, DNA2 (DNA replication helicase/nuclease 2) and EXO1 (Exonuclease 1) proteins bind the DNA to cut for a longer distance, which is important for single-strand DNA invasion, homologous recombination, and activation of ATR $[17,24,25]$. The activation of ATM depends on the interaction between Mre11 and Nbs1. ATM phosphorylates many repair proteins, including H2AX, Mre11, Nbs1, Sae2/CtIP (SUMO-activating enzyme 2/CTBP-interacting protein), CHK1 (checkpoint kinase 1), CHK2 (checkpoint kinase 2), and ATM itself, leading to cell cycle arrest and DNA repair pathway activation [26,27].

Mutation of Mre11 or Rad50 in Arabidopsis led to abortion of siliques and showed high sensitivity to damage agents. In the two mutants, ATR, but not ATM, phosphorylates the histone $\mathrm{H} 2 \mathrm{AX}$, and the ATR-dependent phosphorylation is accumulated extensively in the S-phase nucleus $[12,28,29]$. Moreover, the mutation of the Mre11 gene leads to loss of some chromosomes and DNA repair ability, and increases the sensitivity to damage agents [30,31]. In Caenorhabditis elegans, the Mre11 gene plays an important role in meiosis. There is no crossing-over formation during meiosis of the mre11 mutant, while the synapsis is normal [32]. In mouse, loss of Mre11 nuclease activity increases genomic instability and early embryonic lethality [33]. In humans, the mre11 mutant gives rise to ataxiatelangiectasia-like disorder [34]. In rice, the homolog of Mre11 has been identified and functions in meiotic progression. When OsMre11 is not expressed, neither homologous synapsis nor the end of DNA processing can push forward normally [35]. Nonsense mutations in the Nbs1 gene are fatal to mammals, because Nbs1 cannot mediate DNAdamage signaling and recruit ATM to the damage sites for precise repair [36]. In humans, Nbs1 is considered to be the genetic basis of Nijmegen breakage syndrome (NBS) which is 
a rare disease connected to chromosomal instability. The clinical feature of the disease is irradiation sensitivity, cancer susceptibility, immunodeficiency, short stature, microcephaly, and intellectual disability [34].

This work provides new insight into future investigations aimed at understanding the molecular mechanisms of Mre11 in DNA replication and damage repair during the mitosis of rice.

\section{Results}

2.1. Mre11 Is Conserved in Various Species and Expressed Extensively during the Growth and Development of Rice

To investigate the conservation of the Mre11 protein among various species, the fulllength amino acid sequences of OsMre11 and its orthologs were subjected to sequence comparison (Figure S1). The result showed that OsMre11 and its orthologs exhibit a relatively conserved amino acid sequence. By analyzing the structure of OsMre11 protein (http:/ / pfam.xfam.org/ search\#tabview=tab1), we found that it contains two functional domains, metallophos phosphoesterase and DNA-binding domains (Figure S1). Further phylogenetic analysis showed that Mre11 proteins were widespread in prokaryotes, animals, and higher plants (Figure S2).

To investigate the temporal and spatial expression pattern of OsMre11, we detected the transcriptional level of OsMre11 in different vegetative and reproductive tissues via qRT-PCR assay and found that OsMre11 was widely expressed in all examined tissues, with relatively high expression values in $60 \mathrm{~d}$ leaves and 30DAP seeds (Figure 1a). Furthermore, the OsMre11-driven tissue-specific GUS ( $\beta$-Galactosidase) expression analysis showed that OsMre11 was expressed in young leaf, root and root tip (Figure 1b), shoot apical meristem (SAM) (Figure 1c), pistil, stamen (Figure 1d), 60-day-old stem (Figure 1e), mature seed (Figure 1f), and callus (Figure 1g). To investigate the subcellular localization of OsMre11 protein, the 35S::Mre11-GFP vector was constructed and transferred into tobacco leaf epidermis. Fluorescence observation showed that the GFP signals were specifically localized in the nuclei (Figure 1h). These results suggest that OsMre11 is a conserved nucleoprotein that may have vital functions in multiple developmental stages of rice.

\subsection{Knock-Out of OsMre11 Causes Dwarfism of the Rice Plant}

To investigate the function of OsMre11 in rice, the T-DNA mutant was first identified, and the primers were designed to identify the precise mutation position. The result showed that the T-DNA insertion site of the mre11 was located in the 19th intron of OsMre11 (Figure 2a). Through genotypic identification in the progenies, we obtained wild type (WT), heterozygous (HZ), and homozygous (HM) plants (Figure 2b) and found that there was no OsMre11 expression near T-DNA insertion in the 3rd and 6th homozygous plants by semi-quantitative PCR (Polymerase Chain Reaction) technique (Figure 2c). Furthermore, the phenotype characteristics of all genotypes were observed, and no developmental defects appeared in WT or heterozygote plants during vegetative growth, whereas the homozygous plants of the mre11 mutant were dwarf (Figure 2e). To verify that the dwarf phenotype was caused by the mutation of Mre11 in rice, the complementation assay was performed by transforming the full-length genomic fragment of OsMre11 into the mre11 callus, forming transgenic plants. We found that vegetative growth and gene expression of the complementary plants (mre11-com) returned to normal levels (Figure 2e,f). Simultaneously, the CRISPR/Cas9 (clustered regularly interspaced short palindromic repeats/Cas9) system was used to create another mutant $m r e 11-c r$. In this mutant, the editing site was located in the 19th exon close to the T-DNA (Figure 2a), and sequencing of PCR amplified OsMre11 genomic DNA from rice transgenic positive plants showed that each chain of DNA inserted a guanine base, indicating it was a homozygous mutant (mre11-cr) (Figure 2d). Although the OsMre11 expression level in the mre11-cr mutant was close to rice WT and the complementary plants (Figure 2f), the phenotype analysis showed that the development characteristics of mre11-cr were similar to the T-DNA mre11 mutant (Figure 2e,g). Because 
mre11-cr had a point mutation, the mutant had no effect on its gene expression. These results indicate that OsMre11 is essential for normal vegetative growth and development in rice.
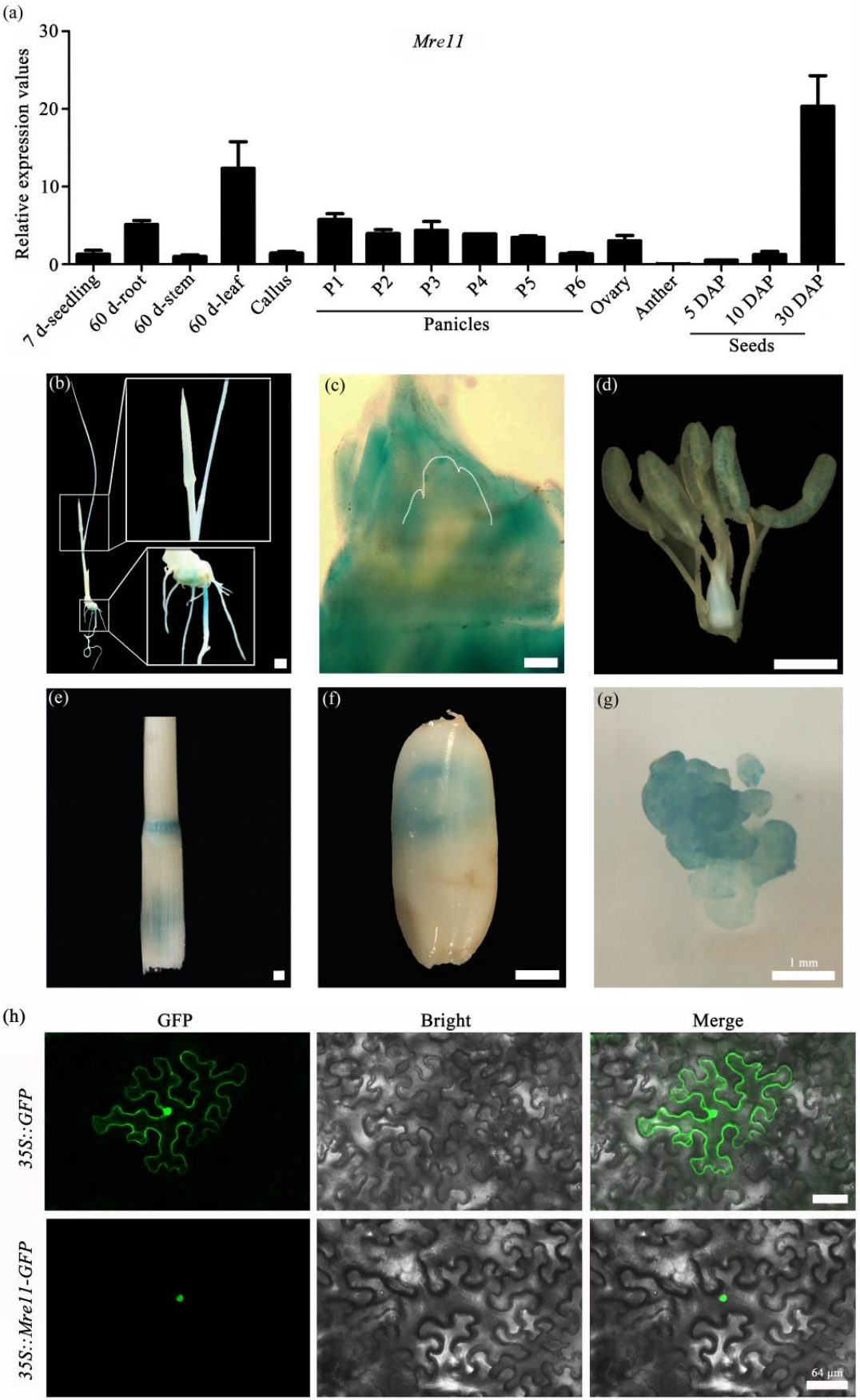

Figure 1. Expression pattern of OsMre11 gene in rice. Expression pattern of OsMre11 gene in rice. (a) Expression level of OsMre11 gene in 7-day-old seedling, 60-day-old root, 60-day-old stem, 60-day-old leaf, callus, panicles (P1: 0-3 cm spikelet; P2: 3-5 cm spikelet; P3: 5-10 cm spikelet; P4: 10-15 cm spikelet; P5: 15-22cm spikelet; P6: 22-30cm spikelet), ovary, anther, and seeds (5DAP: 5 days after pollination; 10DAP: 10 days after pollination; 30DAP: 30 days after pollination). (b-g) GUS ( $\beta$-Galactosidase) expression pattern in different tissues and organs. GUS expression in 7-day-old seedling after germination $(\mathbf{b})$, shoot apical meristem $(\mathbf{c})$, pistil and stamen $(\mathbf{d}), 60$-day-old stem (e), mature seed (f), transgenic positive callus $(\mathbf{g}) .(\mathbf{b}, \mathbf{d}-\mathbf{g})$ Scale bars represent $1 \mathrm{~mm}$. (c) Scale bar represents $0.1 \mathrm{~mm}$. (h) Subcellular localization of OsMre11 in tobacco epidermal cells. The 35S::GFP was used as a negative control. Scale bars represent $64 \mu \mathrm{m}$. 
(a)

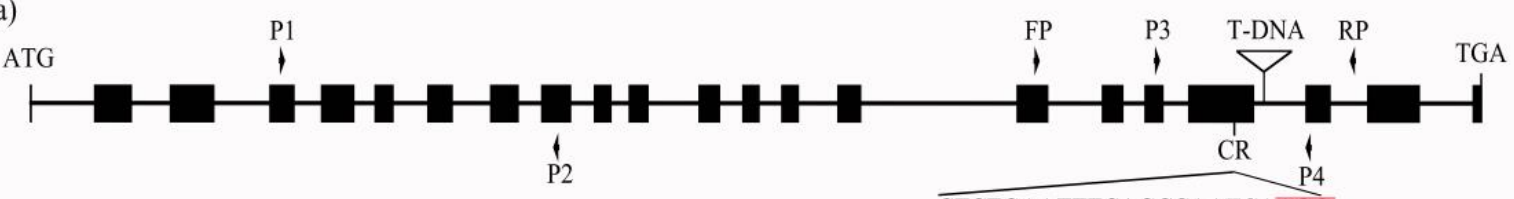

(b)

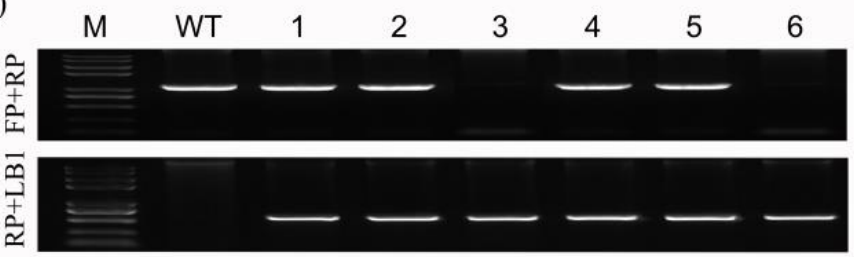

(c)

CTGAATTTCAGCCAATCAAGG

(d) WT : GAAGCAGACCACTCTGAATTTCAGCCAA--TCAAGGTTATTAAATTAATTGCTA

Allele1: GAAGCAGACCACTCTGAATTTCAGCCAAGTCAAGGTTATTAAATTAATTGCTA $(+1$ bp $)$

Allele2: GAAGCAGACCACTCTGAATTTCAGCCAAGTCAAGGTTATTAAATTAATTGCTA $(+1$ bp $)$

(e)

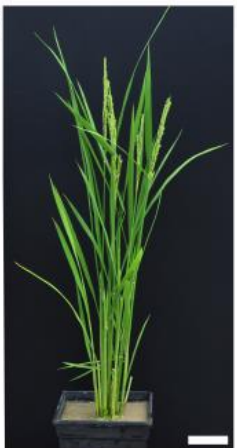

WT

(g)

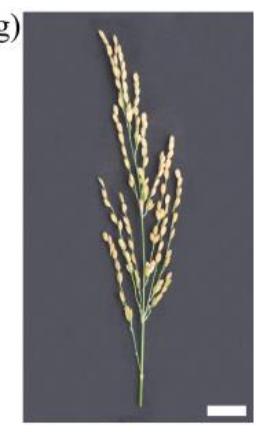

WT

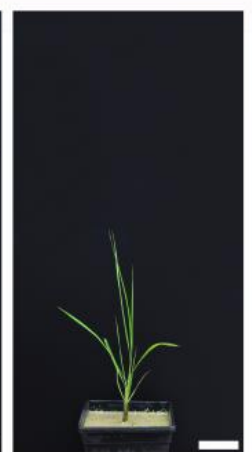

mrell

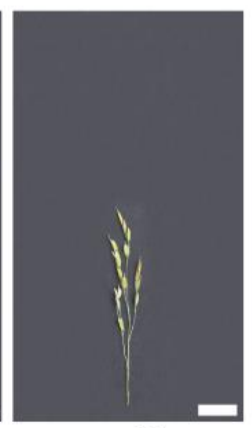

mrell

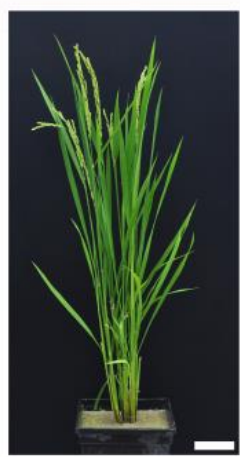

mrell-com

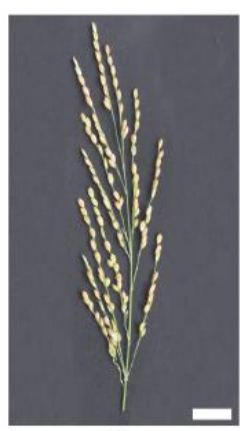

mrell-com

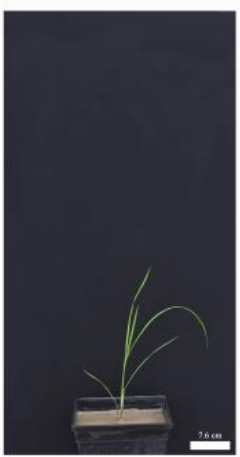

mrel1-cr

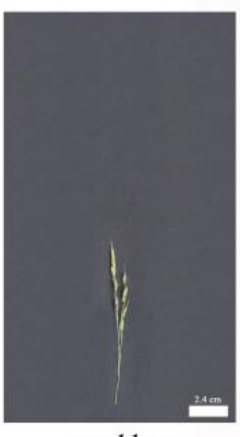

mre11-cr (f)

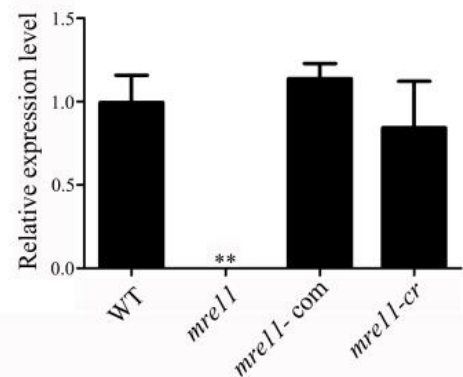

(h)

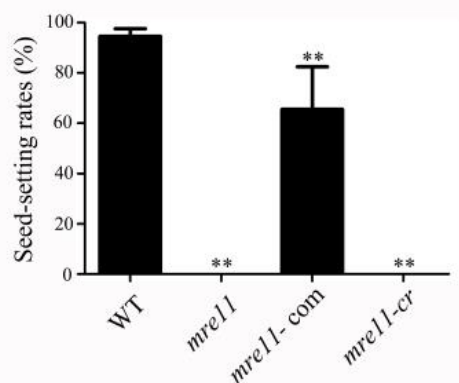

Figure 2. Identification and phenotypic characteristics of the mre11 mutant in rice. Identification and phenotypic characteristics of the mre11 mutant in rice. (a) Schematic diagram of the Mre11 gene in rice shows the positions of T-DNA insertion and CRISPR/Cas9 (clustered regularly interspaced short palindromic repeats/Cas9) editing site. Exons are depicted as black box; while introns are depicted as lines. Red rectangle highlights the CRISPR/Cas9 editing site protospacer adjacent motif sequence. (b) Identification of the homozygous and heterozygous mre11 mutants by assay method of three primers. (c) Semiquantitative analysis of Mre 11 gene in the number 3 and 6 of rice plants. (d) Sequence analysis of Mre 11 mutation site in the mre11-cr plant. An arrow indicates the location of genetic editing site, inserting a base G. (e) Phenotypes of wild-type plant (WT), mre11 mutant plant, complemented plant (mre11-com), and CRISPR/Cas9 transgenic plant (mre11-cr). Scale bars represent $7.6 \mathrm{~cm}$. (f) Relative expression level of OsMre11 gene in WT, mre11, mre11-com, and mre11-cr plants. (g) Panicle phenotypes of WT, mre11, mre11-com, and mre11-cr plants. Scale bars represent $2.4 \mathrm{~cm}$. (h) The average seed-setting rates of each panicle in WT, mre11, mre11-com, and mre11-cr plants. The numbers of panicles are more than 24 . The two asterisks represent a statistically significant difference according to Student's t-test $\left.{ }^{* *}, p<0.01\right)$. 
Moreover, the seed-setting rates were up to $94.61 \%$ in the WT plants and $65.55 \%$ in the mre11-com $\mathrm{T}_{2}$ generation plants, while the seeds of the mre11 and mre11-cr mutants were completely aborted (Figure $2 \mathrm{~h}, \mathrm{~g}$ ). The embryo sac transparency and $\mathrm{KI}^{-\mathrm{I}_{2}}$ staining showed that the female and male gametophytes of $\mathrm{HZ}$ plants had no obvious abnormality, but those of mre11 (HM) were completely aberrant, leading to the aborted seeds (Figure 3a,b). These results suggest that OsMre11 plays a crucial role in the development of female and male gametophytes.
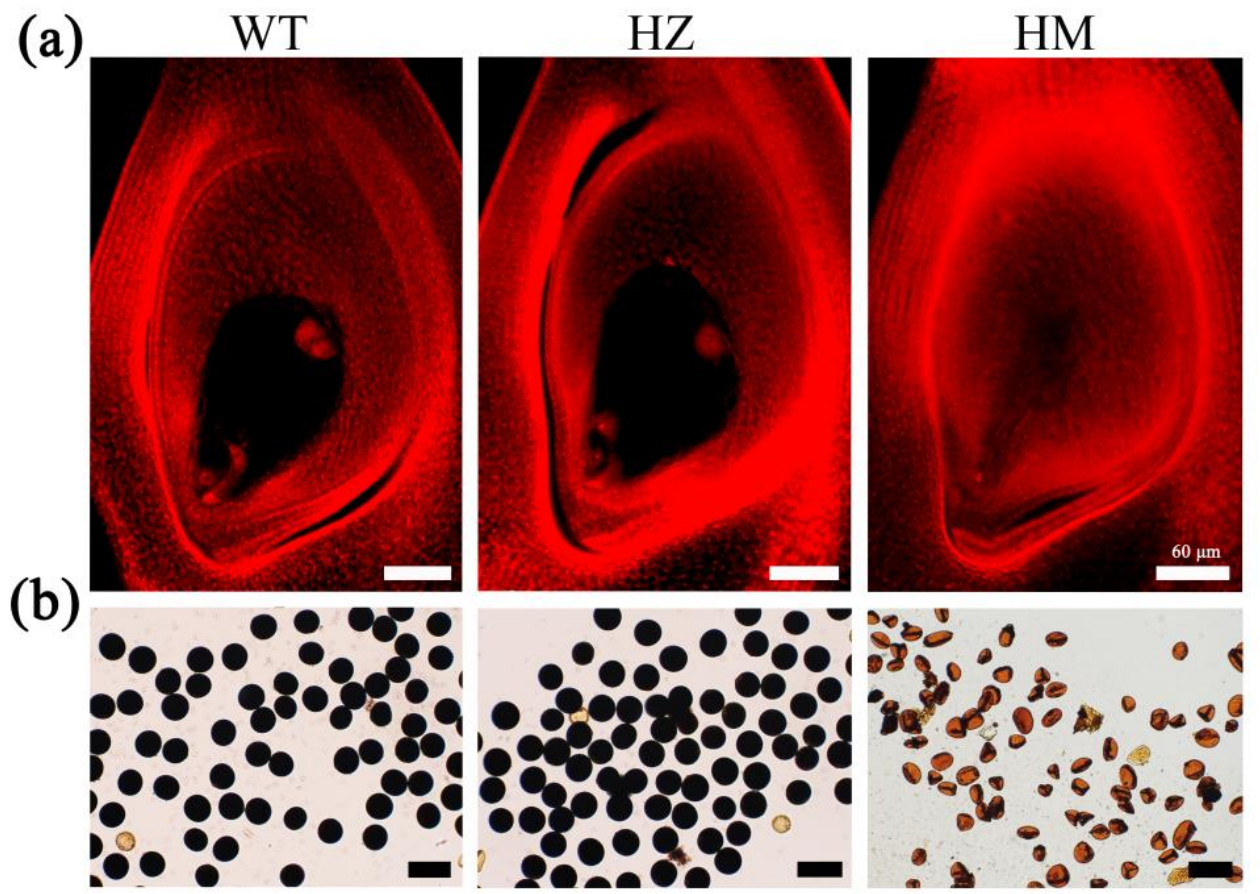

Figure 3. Phenotype characteristics of male and female gametophytes in rice heterozygous and homozygous mutants. Phenotype characteristics of male and female gametophytes in rice heterozygous and homozygous mutants. (a) Pictures of ovary transparency, displaying defective embryo sac in homozygous mutants (HM) compared with wild type (WT) and heterozygous (HZ). (b) Pictures of pollens stained with $\mathrm{KI}_{-} \mathrm{I}_{2}$, showing abortion pollens in HM mutants compared with WT and HZ. Scale bars represent $60 \mu \mathrm{m}$.

For the other two components of the MRN complex, the expression of OsRad50 and OsNbs1 was extensive in the examined tissues and organs (Figure S3a,b), indicating that they are extensively expressed genes similar to OsMre11. These results suggest that Rad50 and Nbs1 may play roles in the growth and development of rice together with Mre11.

\subsection{The Cell Division Activity in the Root Apical Meristem of the mre11 Mutant Was Inhibited}

The shoots and roots of the mre11 seedlings that germinated for 10 days were significantly shorter than those of the WT seedlings (Figure 4a). The average length of shoots and roots was $61.18 \%$ and $42.29 \%$ shorter than the WT seedlings, respectively (Figure $4 \mathrm{~b}$ ). To further observe the cell size and number of the root apical meristem (RAM), we performed the root tip transparent and staining assay in 10-day-old seedlings (Figure 4c), and found that the RAM of the mre11 mutant was $30.36 \%$ shorter in length (Figure $4 \mathrm{~d}$ ), $36.75 \%$ less in cell number (Figure $4 \mathrm{e}$ ), and 14.39\% smaller in cell size (Figure 4f) than the WT seedlings. However, there was no difference in the number of cell layers in the elongation zone (Figure $4 \mathrm{~g}$ ). These results imply that the cell division activity in the mre11 mutant is inhibited. 


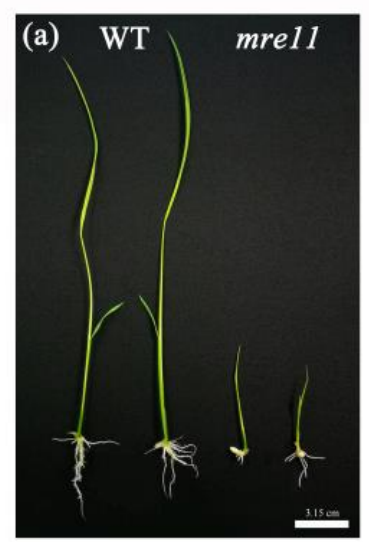

(d)

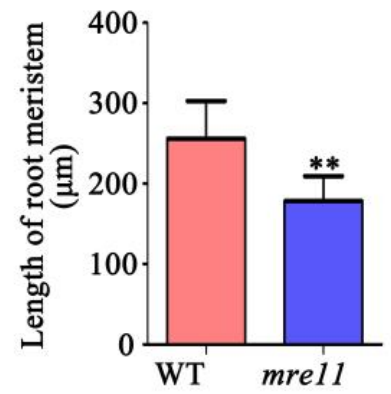

(b)

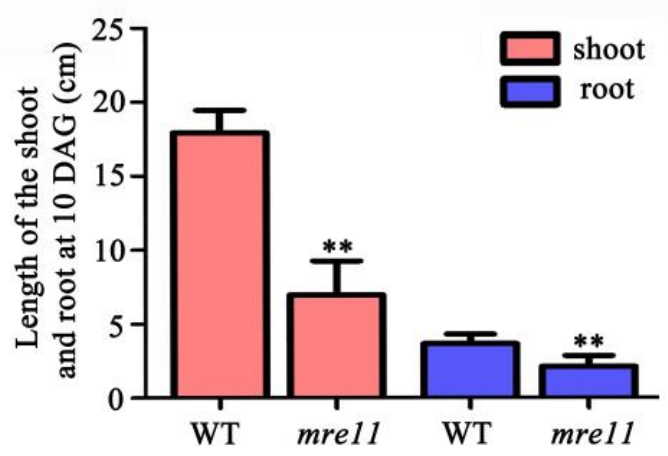

(e)

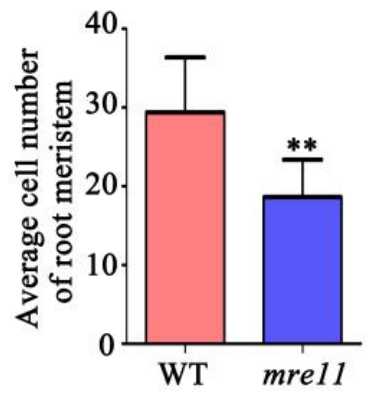

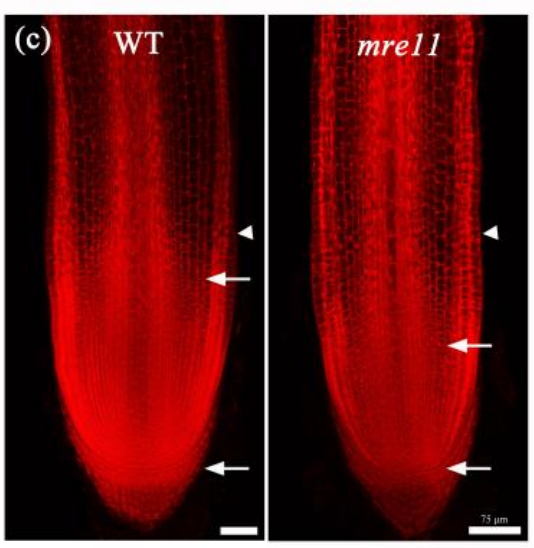

(g)

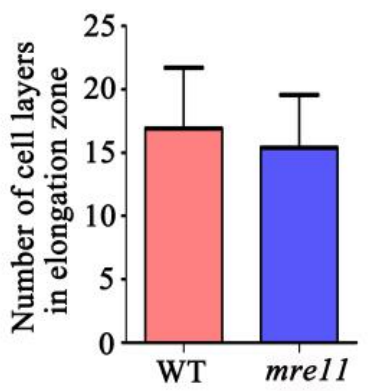

Figure 4. Characteristics of roots in WT (Wild-type) and the mre11 mutant of rice. Characteristics of roots in WT and the mre11 mutant of rice. (a) The phenotypes of 10-day-old WT and the mre11 seedlings. Scale bar represents $3.15 \mathrm{~cm}$. (b) Shoot (red) and root (blue) length of 10-day-old WT and the mre11. The numbers of WT and the mre11 were 40 and 14, respectively. (c) Phenotype characteristics of root apical meristem in the WT and the mre11 of rice. The two arrows indicated the areas of root apical meristem. The two arrowhead in each root showed the location of counting cell layers from outside to inside in elongation zone of the root tip. Scale bars represent $75 \mu \mathrm{m}$. (d) The analysis in length of root apical meristem. (e) Average cell number of root apical meristem. (f) Average cell size of root apical meristem. (g) Number of cell layers from outside to inside in root elongation zone. $(\mathbf{d}-\mathbf{g})$ The numbers of WT and the mre11 are 37 and 31, respectively. The two asterisks represent a statistically significant difference according to Student's t-test $\left.{ }^{* *}, p<0.01\right)$.

\subsection{Mitotic Division Is Aberrant in the Root Apical Meristem of the mre11 Seedlings}

To investigate the defect in cell division in the mre11 mutant, the mitotic chromosome morphology and segregation in the root tip cells were analyzed. As shown in Figure 5, chromatin was condensed to form chromosomes in prophase (Figure 5a,f,k,p), and the chromosomes of WT and mre11-com were regularly arranged on the equatorial plate in metaphase (Figure 5b,1), while there were many chromosomal fragments near the equatorial plates in the mre11 and mre11-cr mutants (Figure $5 \mathrm{~g}, \mathrm{q}$ ). In anaphase, sister chromatids of chromosomes moved to the two poles of cells, while some cells contained lagging chromosomal fragments and chromosomal bridges in the mre11 and mre11-cr but not in WT and mre11-com (Figure 5c,d,h,i,m,n,r,s). In telophase, two daughter cells were generated (Figure 5e,j,o,t). The chromosome abnormal ratio reached up to $25.86 \%(n=58)$ in the mre 11 and $34.78 \%(n=23)$ in the mre11-cr seedlings, while there was no abnormities in WT $(n=76)$ and mre11-com $(n=41)$ seedlings. The results indicate that OsMre11 is required for ensuring well-balanced mitosis in rice growth and development. 


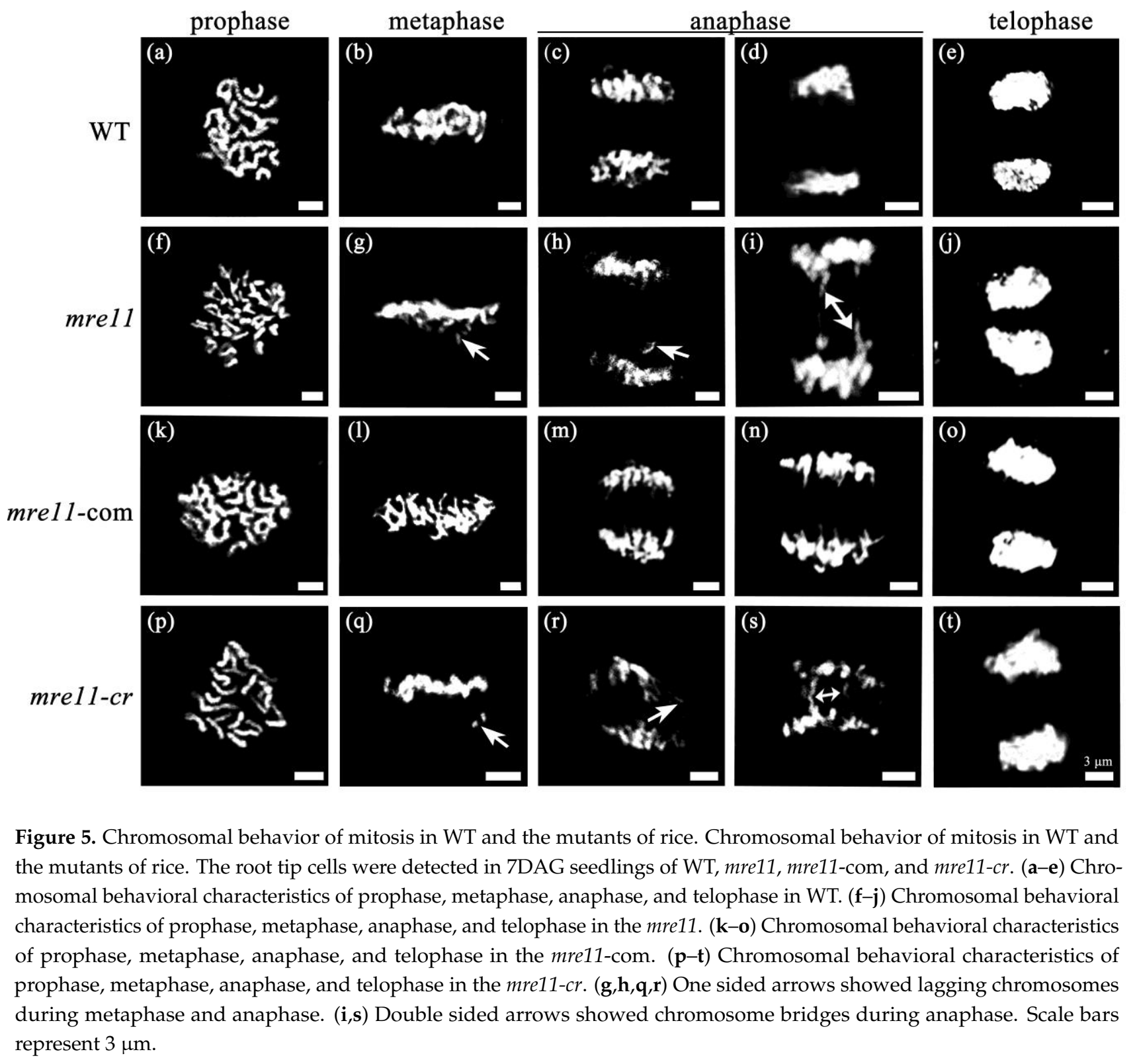

\subsection{OsMre11 Functions in DNA Replication during Mitosis}

A single cell cycle includes two stages, interphase and a mitotic division phase. Interphase is an active material preparation stage for mitosis, completing the replication of DNA molecules and the synthesis of related proteins. Interphase is divided into G1, $\mathrm{S}$, and G2 phases, and DNA replication is mainly in S phase. To elucidate the role of OsMre11 in the cell cycle, DNA replication inhibitors hydroxyurea (HU) and aphidicolin were applied to treat the 10 DAG seedlings. The results showed that the expression of OsMre11 increased with the HU treatment (Figure 6a), but no obvious change was observed with the aphidicolin treatment (Figure S4a,b). Ethynyl deoxyuridine (EdU), an analog of thymidine, can be incorporated into chromosomes during DNA replication, and it is often used to label S-phase cells [37]. A staining assay with EdU showed that there was an obviously lower proportion of EdU-labeled cells in the RAM of mre11 than those in WT (Figure $6 \mathrm{~b}, \mathrm{c}$ ), and the ratio of EdU-labeled cells among the number of cells in RAM of the mre11 was significantly lower than that of WT (Figure 6d), indicating that S-phase DNA replication is impaired in the mre11 seedlings. Therefore, OsMre11 is a critical factor for mitotic DNA replication in rice. 

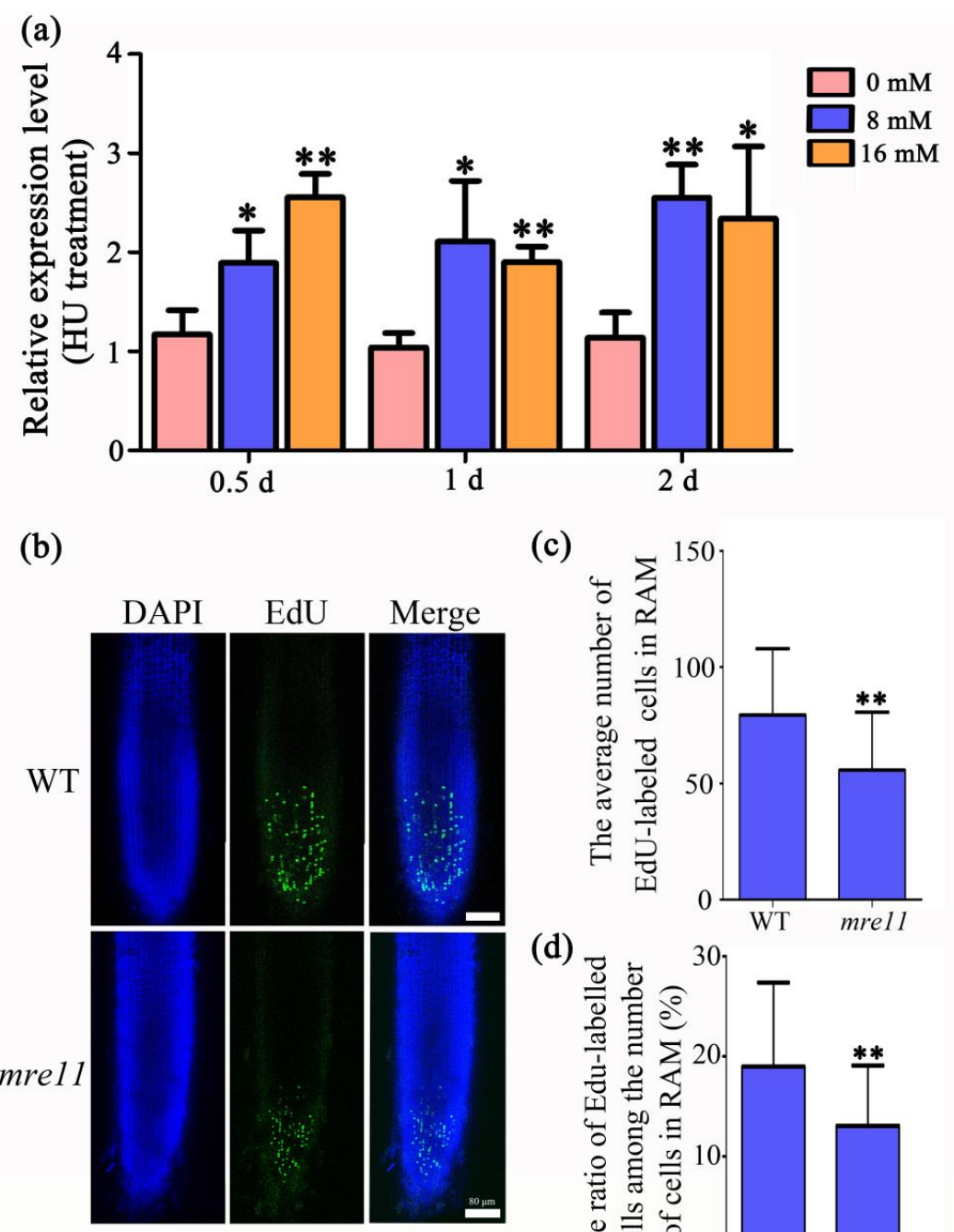

(c)
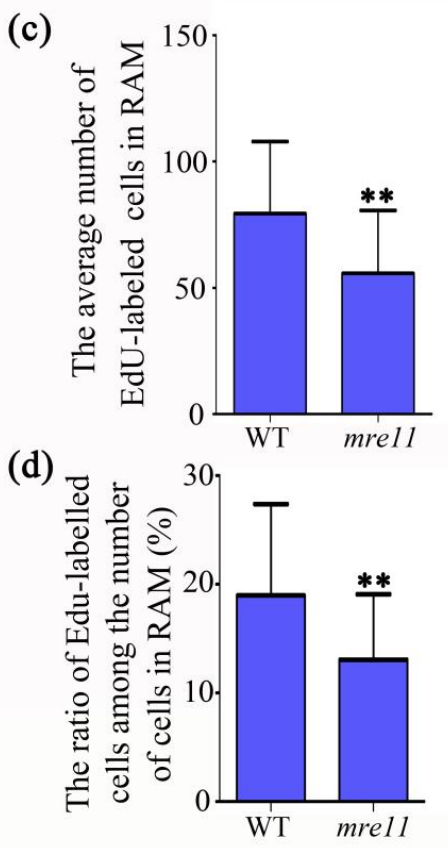

Figure 6. OsMre11 is involved in DNA replication of rice root. OsMre11 is involved in DNA replication of rice root. (a) Relative expression level of Mre 11 with the treatment of $\mathrm{HU}$. The concentration of $\mathrm{HU}$ is 0,8 , and $16 \mathrm{mM}$. The materials were collected after the treatment of $0.5,1$, and 2 days. (b) Signals of ethynyl deoxyuridine (EdU) staining in 7DAG roots of rice WT and mre11 seedlings. DAPI is 4', 6-diamidino-2- phenylindole dihydrochloride. Scale bars represent $80 \mu \mathrm{m}$. (c) The average number of EdU-labeled cells in root apical meristem. (d) The ratio of EdU-labeled cells among the number of cells in root apical meristem. The numbers of WT and the mre11 are 24 and 18, respectively. The asterisks represent a statistically significant difference according to Student's $t$-test $\left.{ }^{*}, p<0.05 ;{ }^{* *}, p<0.01\right)$.

\subsection{OsMre11 Is Essential for DNA Damage Repair in Somatic Cells}

To prove whether the mutation of OsMre11 was involved in the DNA damage response, the WT seedlings were treated with methyl methanesulfonate (MMS) and mitomycin C (MMC) to detect the expression level of OsMre11. MMS and MMC are both DNA damage reagents. MMS can only cause double strand breaks, while MMC can cause single strand breaks or double strand breaks. The results showed that the expression of OsMre11 was up-regulated after treatment with the MMS reagent (Figure 7a), but there was no change after treatment with the MMC reagent (Figure S4c,d), suggesting that OsMre11 has a higher sensitivity to MMS and may be involved in DSB repair. To verify this finding, we conducted a comet assay, also known as single-cell gel electrophoresis, to evaluate the strength of genotoxicity by detecting the degree of DNA strand damage (Figure $7 \mathrm{~b}$ ). The comet assay 
can effectively detect and quantify the extent of DNA single- and double-strand breakage in cells [38]. The more severe the DNA was damaged, the more fragments were produced, the more DNA breaks migrated under the same electrophoresis conditions, and the longer the migration distance. CometScore software calculation showed that DNA content in tails of the mre11 mutant was nearly 1.44 times of WT (Figure 7c), indicating that OsMre11 plays an important role in DNA DSB repair.

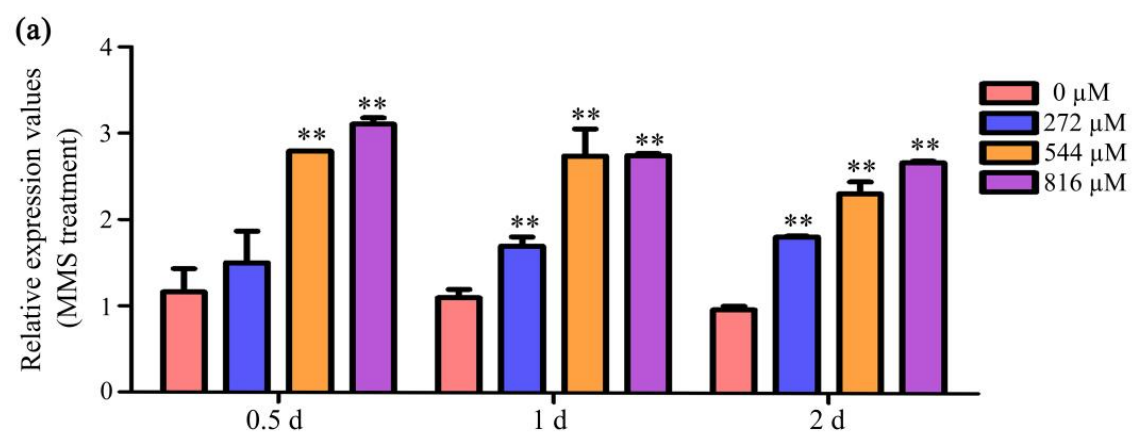

(b)

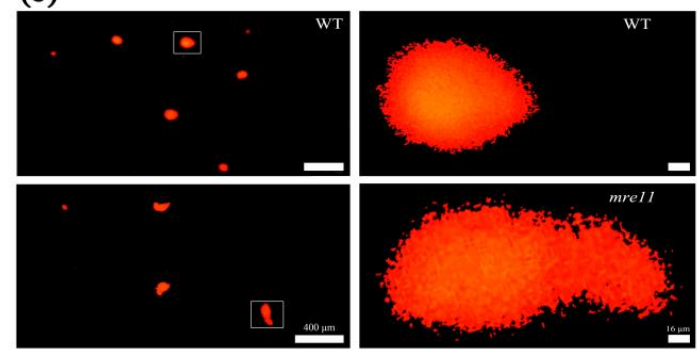

(c)

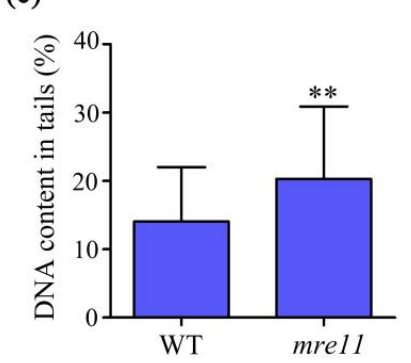

Figure 7. OsMre11 is involved in DNA damage repair of rice. OsMre11 is involved in DNA damage repair of rice. (a) Relative expression level of OsMre11 in the 10DAG seedlings with the treatment of MMS reagent. The concentration of MMS was $0,272,544$, and $816 \mu \mathrm{M}$, respectively. Materials were collected after the treatment of $0.5,1$, and 2 days. (b) Pictures of comet assay in the 10DAG seedling roots of WT and mre11. The images on the right are magnified images in the white boxes on the left. Scale bars represent $400 \mu \mathrm{m}$ on the left and $16 \mu \mathrm{m}$ on the right. (c) The DNA contents of the tail of nuclei in root cells of WT and the mre11 seedlings. The numbers of WT and the mre11 are 82 and 76, respectively. The two asterisks represent a statistically significant difference according to Student's t-test $(* *, p<0.01)$.

\subsection{OsMre11 Plays Crucial Roles through Interacting with OsRad50 and OsNbs1}

To further study the conservation of OsMre11 at the secondary structure level, we constructed the three-dimensional structure in different species based on the homolog CtMre11 in Chaetomium thermophilum (Figure S5). The Mre11 proteins exhibited a high degree of similarity in the secondary structure and can form a dimer with itself. In humans, yeast, and Arabidopsis, Mre11 can interact with Rad50 and Nbs1 to play biological roles together $[12,39,40]$, but it is not clear whether Mre11 can interact with Rad50 and Nbs1 in rice. Therefore, we constructed the secondary structure of Rad50 and Nbs1 (Figure S5) and found that they were similar and conserved in various species. Rad50 could also form a dimer by itself, but Nbs1 could not.

Subsequently, we performed a bimolecular fluorescence complementation (BiFC) assay in tobacco leaves using a transient transformation technique and detected that the YFP signals in transformed leaf cells co-expressing the constructs OsMre11-YN and OsMre11-YC, OsRad50-YN and OsRad50-YC, OsMre11-YN and OsRad50-YC, OsMre11YN and OsNbs1-YC, OsRad50-YN and OsMre11-YC, and OsNbs1-YN and OsMre11-YC (Figure S6). The results showed that OsMre11 and OsRad50 can interact with themselves (Figure S6b,d), but OsNbs1 cannot (Figure S6f). OsMre11 can interact with OsRad50 
and OsNbs1 (Figure S6g-i,k), but OsRad50 cannot interact with OsNbs1 (Figure S6j,1). To further verify the interactive relationship between OsMre11, OsRad50, and OsNbs1, coimmunoprecipitation tests and analysis were conducted (Figure 8). When the three fused proteins, OsMre11-GFP, OsRad50-3×Flag, and OsNbs1-3×Myc were transiently co-expressed in tobacco leaf cells, the OsMre11-GFP and OsRad50-3 $\times$ Flag fusion proteins could be coimmunoprecipitated with OsNbs1-3 $\times$ Myc (Figure $8 \mathrm{a}$ ). When two fused proteins, OsMre11-GFP and OsRad50-3 $\times$ Flag were transiently co-expressed in tobacco leaf cells, OsMre11-GFP could be coimmunoprecipitated with OsRad50-3 $\times$ Flag (Figure 8b). When OsMre11-GFP and OsNbs1-3×Myc were transiently co-expressed in tobacco leaf cells, OsMre11-GFP could be coimmunoprecipitated with OsNbs1-3×Myc (Figure $8 \mathrm{c}$ ). However, when OsRad50-3 $\times$ Flag and OsNbs1-3 $\times$ Myc were transiently co-expressed in tobacco leaf cells, OsRad50-3 $\times$ Flag could not be coimmunoprecipitated with OsNbs1-3 $\times$ Myc (Figure $8 \mathrm{~d}$ ). Therefore, the results suggest that OsMre11 may act as an intermediate bridge to connect OsRad50 and OsNbs1, forming the Rad50-Mre11-Nbs1 complex to function together in rice growth and development.

(a)

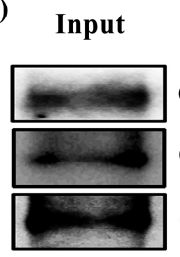

OsNbs1-3×Myc

OsMre11-GFP

OsRad50-3 × Flag

(b)

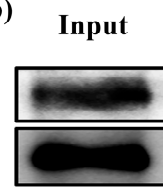

OsRad50-3 × Flag

OsMre11-GFP

(c)

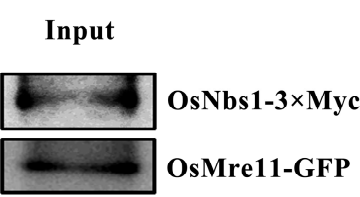

(d)

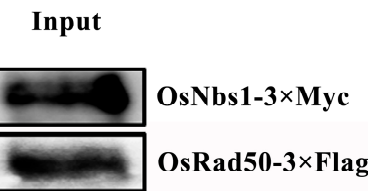

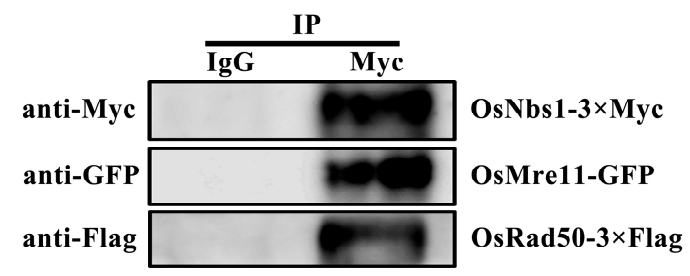

IP

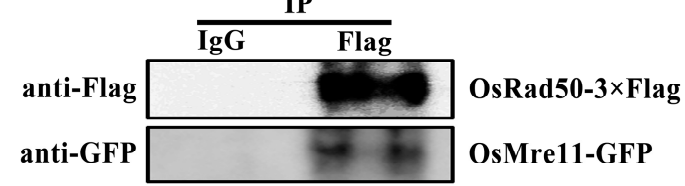

IP

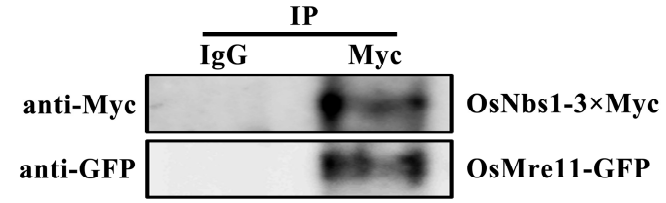

IP

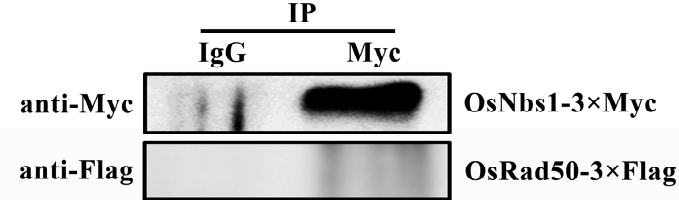

Figure 8. The interaction relationship between OsMre11, OsRad50, and OsNbs1 by coimmunoprecipitation (Co-IP) assay. The interaction relationship between OsMre11, OsRad50, and OsNbs1 by coimmunoprecipitation (Co-IP) assay. (a) The 35S::OsNbs1-3×Myc, 35S::OsMre11-GFP, and 35S::OsRad50-3×Flag were immunoprecipitated using anti-Myc antibody, and analyzed using anti-Myc, anti-GFP, and anti-Flag antibodies. (b) The 35S::OsRad50-3 $\times$ Flag and 35S::OsMre11-GFP were immunoprecipitated using anti-Flag antibody, and analyzed using anti-Flag and anti-GFP antibodies. (c) The 35S::OsNbs1$3 \times$ Myc and 35S::OsMre11-GFP were immunoprecipitated using anti-Myc antibody, and analyzed using anti-Myc and anti-GFP antibodies. (d) The 35S::OsNbs1-3 $\times$ Myc and 35S::OsRad50-3 $\times$ Flag were immunoprecipitated using anti-Myc antibody, and analyzed using anti-Myc and anti-Flag antibodies. (a-d) IgG was the negative control group.

\subsection{Transcriptome Comparative Analysis of Rice Wild Type and the mre11 Mutant}

To further research the effects of OsMre11 mutation on gene expression, a transcriptome analysis of WT and the mre11 seedlings was performed. The column chart of differentially expressed genes, at least a two-fold difference in expression level, showed that 2978 genes were up-regulated and 2396 genes were down-regulated (Figure S7a) in the mre11 mutant compared with WT. Classification analysis of gene ontology (GO) based on 
RNA-seq data showed that the majority of the genes in the mre11 mutant involved in biological process, molecular function, and cellular component were up-regulated (Figure S7b). Further observation on the number of genes in the Kyoto Encyclopedia of Genes and Genomes (KEGG) pathway showed that the expression of many genes related to replication and repair had changed significantly in the mre11 compared with WT, indicating that the DNA replication and repair pathways were activated to some extent (Figure 9a). Among the KEGG pathway results, the expression of some genes involved in homologous recombination repair pathway and non-homologous end joining repair pathway were changed, such as Mre11, RPA, BRCA2, Rad51, Rad54, plo , BLM, Mus81, and XLF [41-44]. These results indicate that OsMre11 may function in the cell biological process, including cell division, DNA replication, and damage repair. To further verify the possibility, we performed the qRT-PCR experiment and found that the expression level of 12 genes related to DNA replication ( $M C M 3, M C M 6, M C M 7$, and ORC5), cell cycle (cyclin-A3-2, cyclin-B2-2, cyclin-D3-1, and cyclin-D6-1), and DNA repair (ATR, Rad51, Mus81, and XLF) changed significantly in the mre11 compared with WT (Figure 9b), indicating OsMre11 may be involved in the events of DNA replication, cell cycle, and DNA damage repair.

(a)

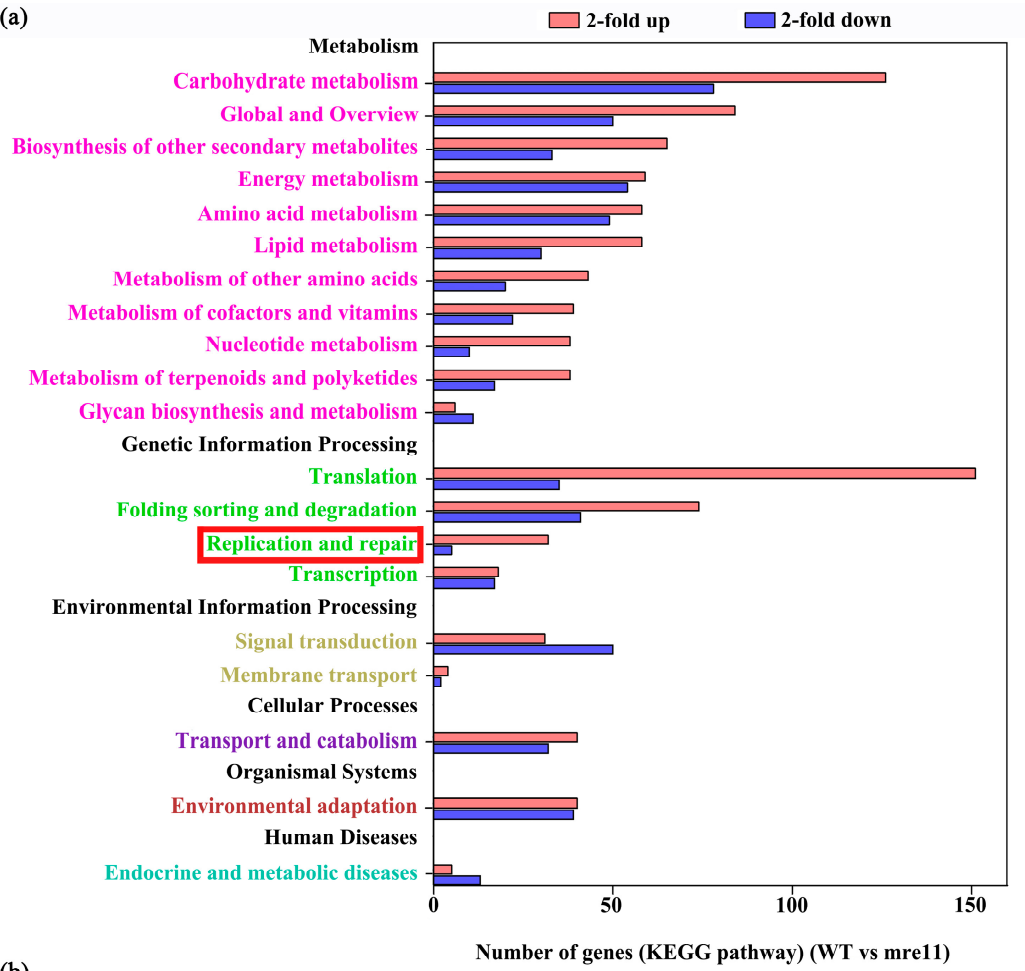

(b)

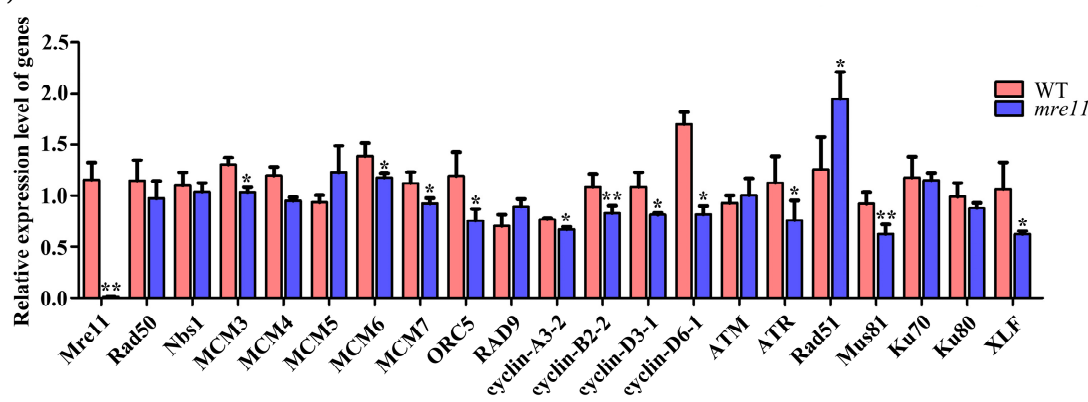

Figure 9. RNA sequencing analysis and verification of gene expression in rice WT and the mre11 seedlings. RNA sequencing analysis and verification of gene expression in rice WT and the mre11 seedlings. (a) The number of 2-fold up and downregulated genes in the Kyoto Encyclopedia of Genes and Genomes (KEGG) pathway (WT vs. mre11). Many genes related to replication and repair had changed significantly in the mre11 compared with WT (in the red frame). (b) The relative expression level of genes related to DNA replication, cell cycle, and DNA repair in WT and the mre11 seedlings. The asterisks represent a statistically significant difference according to Student's t-test $\left({ }^{*}, 0.01<p<0.05 ;{ }^{*}, p<0.01\right)$. 


\section{Discussion}

\subsection{Mre11 Is Indispensable for Growth and Development}

Mre11 is a nuclease and central component of the MRN complex. When DNA is damaged due to various factors, Mre11 can bind to the damaged DNA ends and excise them [17]. When DNA is unaffected, whether Mre11 excises the DNA ends, is controlled by the protein C1QBP. C1QBP binds to Mre11 directly to form the MRC (Mre11, Rad50, and (1QBP) complex to stabilize Mre11 and limit its nuclease activity [13].

In Saccharomyces cerevisiae, the Mre11 protein contains two functional domains, a nuclease domain in the N-terminus required for DSB repair, and the dsDNA-binding domain in the C-terminus essential for its meiotic functions such as DSB formation and chromatin modification [45]. In this study, we found that the OsMre11 protein also contains two functional domains (Figure S1), a metallophos phosphoesterase domain near the $\mathrm{N}$-terminus and a DNA-binding domain close to the C-terminus. Phosphoesterase domains are usually associated with DNA polymerases, while DNA-binding domains can promote the implementation of nuclease activity [46].

The first Mre11 homolog was found in the screening of meiotic mutants of S. cerevisiae. The mutation of Mre11 (also known as rad32) in fission yeast leads to increased chromosome loss, indicating that Mre11 plays an important role in maintaining the stability of chromosomes [31]. In Caenorhabditis elegans, the germ cells of the mre-11 mutants with the treatment of $\gamma$-irradiation generated chromosomal abnormality during meiotic prophase I, indicating that the chromosomal damage repair in these germ cells was defective [32]. In humans, mutation of Mre11 can cause ataxia-type telangiectasia-like disease (ATLD), which is characterized by chromosomal instability, radiation hypersensitivity, neurological deficits, and susceptibility to certain types of cancer [47]. When the N117S mutation occurs in $h M r e 11$, the interaction between Mre11 and Nbs1 in most ATLD patients weakens, the telomere length becomes unstable, and ATM cannot be recruited to repair the damaged DNA [48]. In Arabidopsis, the T-DNA inserted mutant mre11-1 was abnormally developed, with dwarf plants, small siliques, few fertile seeds, and high sensitivity to damage agents. The telomere length of the mutant was increased, and the C-terminal domain of the Mre11 protein was closely related to telomere maintenance [49]. In our study, the OsMre11 gene is widely expressed in various tissues and organs of rice (Figure 1), implying that it may function in various stages of plant growth and development. In the mre11 of rice, vegetative growth and reproductive development were both defective, with dwarf plants and completely aborted seeds (Figure 2). The results indicate that OsMre11 plays essential roles in plant growth and development of rice.

\subsection{OsMre11 Is Essential for Rice Mitosis}

Cell division plays an essential role in plant growth and development. In Arabidopsis-related research, cell division was reduced, the primary root became shorter, and the length of the RAM decreased significantly in the nse1-1, nse3-1, and $r f c 4$ partially complemented mutant. The NSE1 and NSE3 genes can promote DNA damage repair during mitosis. The RFC4 that is involved in DNA replication and mitosis [50,51]. The full-length of the Mre11 protein in Arabidopsis is necessary for cell cycle arrest and transcriptional regulation. When the Mre11 was mutated, the expression of cell cycle-related genes and transcription-related genes changed significantly [52]. In rice, the mitotic cell cycle of the alr mutant was abnormal, leading to delayed plant growth and decreased cell number. Further research showed that the transition of the cell cycle from G1/S to G2/M was blocked in the alr mutant. The phenotypic characteristics of the alr mutant are albinic leaves, dwarf stature, and necrotic lesions [53].

In this study, we found that the root length of rice mre11 was shorter, the cell number was lower, and the cell size was smaller in mre11 RAM than WT through a root tip transparent and staining assay (Figure 4). Further study showed that mitotic division was aberrant in the RAM of the mre11 seedlings (Figure 5). The appearance of chromosomal fragments and chromosomal bridges in the mre11 RAM of rice caused abnormal mitotic 
divisions. The ratio of EdU-labeled cells in the RAM of the mre11 mutants were significantly lower than those in WT. Treatment with a replication inhibitor also showed that Mre11 was very sensitive to the replication inhibitor HU (Figure 6), but not sensitive to aphidicolin (Figure S4a,b), indicating that Mre11 responds differently to various replication inhibitors. $\mathrm{HU}$ is a reversible ribonucleotide reductase inhibitor, and the treatment with HU depletes nucleotides and prevents cells from entering $S$ phase [54]. Aphidicolin can directly inhibit DNA polymerase activity, causing cells to stall at $S$ phase [55]. Due to the different targets treated by different reagents, the sensitivity of Mre11 to the reagents may also be different. Furthermore, we found that the expression of genes involved in DNA replication and the cell cycle decreased significantly in the mre11 mutants (Figure 9b), indicating that Mre11 may participate in the process of mitosis by affecting the expression of genes related to replication and the cell cycle. The changes in the expression of these genes may be caused by developmental defects resulting from the mutation of the Mre11 gene. It may tell us that the abnormal DNA replication causes the disorder of mitosis, and fewer cell numbers, resulting in stunted plant growth. Therefore, Mre11 has an essential role in DNA replication during the process of the mitotic cell cycle.

When mitosis is disordered, chromosome are unstable, and DNA damage occurs in the cell. Then, repair proteins must repair the damage. In addition, chromosome abnormality can also cause the cell cycle arrest. After the repair is completed, the cell cycle continues [56,57]. As an important member of damage repair, MRN responds to DNA damage in different species. In S. cerevisiae, the GFP-labeled repair proteins as florescent markers were used to label the location of chromosomes in living cells. If the MRX complex congregated in large numbers at the end of severely damaged chromosomes, it indicated that the complex is able to generate a response to the DNA damage [58-60]. In humans, targeted genome editing was performed in HEK293 cells, and the activation of DNA repair mechanisms, including MRN, could be induced [61]. In Arabidopsis, $\gamma$-irradiation caused the production of DSBs, which led to MRN-dependent activation of ATM and ATR kinases [12].

In our study, when WT plants were treated with DNA damage reagent MMS, the Mre11 gene was strongly up-regulated (Figure 7), but when plants were treated with MMC, there was almost no Mre11 response (Figure S4c,d). MMS is a DNA damaging agent and mainly acts on the N7 and N3 deoxyguanosines of DNA molecules, resulting in the formation of DNA double strand breaks (DSBs) $[62,63]$. MMC is a DNA cross-linking agent that can cause single or double strand breaks [63]. These results suggest that the sensitivity of Mre11 to various damage reagents is different according to the manner of injury. The comet assay showed that DNA damage in the mre11 mutant was much higher than in WT (Figure 7), and the gene expression related to DNA damage repair was changed significantly compared to WT (Figure 9b). Among those genes, it was reported that Rad51 and Mus81 were associated with HR [22,23,64,65], ATR responded to halt cell cycle progression and DNA damage repair [66], and XLF was involved in NHEJ [67]. These results illustrate that OsMre11 plays a role in the process of DNA damage repair, and may participate in both HR and NHEJ repair pathways. Through BiFC and Co-IP experiments, we detected the interactive relationship among OsMre11, OsRad50, and OsNbs1. OsMre11 could form a complex with OsRad50 and OsNbs1 (Figure S6 and Figure 8), suggesting that they may function in damage repair as a complex. Given the abnormal DNA replication in the mre11 mutant of rice, we speculated that the emergence of DNA replication problems causes cells to recruit repair proteins including Mre11 to survive better. However, due to the deletion of the repair protein Mre11 in the mre11 mutant, the accumulation of damaged genomes was caused, further inhibiting DNA replication.

\section{Conclusions}

The different functions of Mre11 in many species and in meiosis have been investigated. In plant-related research, such as in Arabidopsis, the mutation of Mre11 led to abnormal meiosis, cell cycle stagnation, chromosome instability, and failure of DNA damage re- 
pair $[12,28,52,68]$. In rice, Mre11 was required for homologous synapsis and DNA damage repair in meiosis [35], but the role in mitosis was little known. Here, we demonstrate that OsMre11 is indispensable for the growth and development of rice. Loss-of-function of OsMre11 causes abnormal development of male and female gametophytes and finally leads to complete abortion of seeds. Abnormal mitosis leads to a decrease in the number of cells, which ultimately leads to the dwarf plants. Furthermore, the mutation of OsMre11 could affect DNA replication and DSB repair, and the transcriptional response of OsMre11 showed high sensitivity to the replication inhibitor $\mathrm{HU}$ and the damage agent MMS. OsMre11 could form a complex with OsRad50 and OsNbs1, and may function in the mitotic cell cycle of rice via two pathways: HR and NHEJ.

OsMre11 is essential for cell division and plays an important role in DNA replication and damage repair during the mitotic cell cycle. This study can help us better understand the molecular mechanism of Mre11 during DNA replication and repair in rice.

\section{Materials and Methods}

\subsection{Plant Materials and Growth Conditions}

In this study, Oryza sativa japonica Dongjin was used as the wild type plant. The TDNA inserted mutant mre11 was obtained from a RISD-DB Mutant Library (Rice T-DNA Insertion Sequence Database, http:/ / cbi.khu.ac.kr/RISD_DB.html). All plants were cultivated in a greenhouse at Wuhan University at $28-30{ }^{\circ} \mathrm{C}$ with a $14 \mathrm{~h}$ light and $10 \mathrm{~h}$ dark cycle from October to April, and in potted soil under natural conditions the rest of the year. We used the three-primer method to identify the mre11 mutant plants, and used a pair of primers on the genome to amplify the wild-type band, and a pair of primers on the genome and T-DNA to amplify the mutant band.

A 3016 bp upstream DNA fragment before the initiation codon of OsMre11 as the $5^{\prime}$-UTR, all nucleotide sequences $(5184 \mathrm{bp})$ of the open reading frame, and the $2361 \mathrm{bp}$ fragment after the stop codon as the $3^{\prime}$-UTR were used as the full-length sequence information for constructing the complementary vector. Then, this entire fragment was ligated to the $p C A M B I A 2301$ vector for genetic transformation. The background of complementary transgenic plants was mre11. In addition, Osmre11-cr transgenic plants were obtained via CRISPR/Cas9 (clustered regularly interspaced short palindromic repeats/Cas9) technique [69]. The background of all CRISPR transgenic plants was rice variety Dongin.

\subsection{Phylogenetic Analysis}

OsMre11 (LOC_Os04g54340) is a single copy gene in Oryza sativa. The OsMre11 protein shares a relatively conserved domain with its orthologs in other species. Its orthologs were obtained from the NCBI database (National Center for Biotechnology Information) (https: / / www.ncbi.nlm.nih.gov/). The phylogenetic tree was constructed using ClustalIX 1.83 to load the relevant sequence, and MEGA 5.1 to convert the file format to the object document based on the neighbor-joining method (bootstrap $=1000$ ).

The accession numbers of proteins discussed in this article are from the National Center for Biotechnology Information (NCBI), Mre11 (Oryza sativa)- AY935255.1, Mre11 (Arabidopsis thaliana)-OAO95209.1, Mre11 (Homo sapiens)-NP_001317276.1, Mre11 (Vitis vinifera)-XP_010644252.1, Mre11 (Mus musculus)-NP_001297657.1, Mre11 (Populus euphratica)-XP_011044534.1, Mre11 (Zea mays)-ACG43091.1, Mre11 (Sorghum bicolor)- XP_021321224.1, Mre11 (Caenorhabditis elegans)-NP_505736.2, Mre11 (Drosophila melanogaster)-AAD33591.1, Mre11 (Danio rerio)- NP_001307188.1, Mre11 (Saccharomyces cerevisiae)-BAA02017.1, Mre11 (Glycine max)-XP_003539581.1, Mre11 (Nicotiana tabacum)-XP_016437115.1, Mre11 (Triticum aestivum)-SPT20634.1, and Mre11 (Escherichia coli)- AZM66280.1.

\section{3. qRT-PCR Assay}

Total RNAs of vegetative and reproductive organs were extracted using TRIzol ${ }^{\circledR}$ reagent. qRT-PCR (quantitative real-time polymerase chain reaction) was performed using SYBR green fluorescence with a CFX Connect $^{\mathrm{TM}}$ real time system (Bio-Rad) [70]. 
Actin was used as the housekeeping gene to normalize the expression of genes in various RNA samples. Three independent biological replicates and three technical replicates were included during final data analysis. In the tests, all primers are listed in Table S1.

\subsection{GUS Staining}

A 3016 bp upstream DNA fragment before the initiation codon of OsMre11 gene was amplified as the promoter. This promoter was then ligated to the $p C A M B I A-1381 \times b$ vector to construct pMre11::GUS, and invaded into rice Dongjin callus through agrobacteriummediated transformation [71]. Different tissues and organs from transgenic positive plants were obtained for GUS staining analysis. After staining with GUS dye $\left(0.1 \mathrm{~mol} / \mathrm{L} \mathrm{Na}_{3} \mathrm{PO}\right.$, $10 \mathrm{mmol} / \mathrm{L} \mathrm{Na}_{2}$ EDTA, $0.5 \mathrm{mmol} / \mathrm{L} \mathrm{K}_{4}[\mathrm{Fe}(\mathrm{CN}) 6], 0.5 \mathrm{mmol} / \mathrm{L} \mathrm{K}_{3}[\mathrm{Fe}(\mathrm{CN}) 6], 0.5 \mathrm{mg} / \mathrm{mL}$ X-Gluc, $0.5 \%$ Triton-X100), and decolorizing with $75 \%$ and $100 \%$ ethanol, the samples were photographed with a Canon EOS 70D digital camera.

\subsection{Subcellular Localization of OsMre11}

The full-length CDS (without stop codons) of OsMre11 was cloned into 35S-GFP (transformed from mpCAMBIA1300) vector to generate the 35S::OsMre11-GFP. The plasmid was transformed into agrobacterium GV3101, and then injected into tobacco (Nicotiana benthamiana) leaf epidermis cells and incubated for $36 \mathrm{~h}$. The signal of fluorescent proteins was visualized under a Leica SP8 confocal laser-scanning microscope. The excitation and emission wavelengths for green fluorescent protein (GFP) are 488 and $507 \mathrm{~nm}$, respectively.

\subsection{Plant Phenotype Analysis}

The rice roots and ovaries were fixed with FAA (formaldehyde:acetic acid:50\% ethyl alcohol $=5: 6: 89$ ) for at least $24 \mathrm{~h}$, and rehydrated in a series gradient of alcohol. Then, the roots were dyed with eosin B and dehydrated in alcohol, transparent in the methyl salicylate, and photographed under a Leica SP8 confocal microscope.

Root meristem size was determined by measuring the length from the quiescent center to the first elongated cell in the 4th cortex layer. When the length of a cortex cell was twice that of the neighbor cell, it was considered to be the first elongated cortex cell. The average cell number of the root meristem was quantified in the 4th cortex layer [72]. The average cell size of the root meristem was the length of the root meristem divided by the average cell number of the root meristem.

\subsection{Mitosis Assay}

Rice roots were fixed in $4 \%$ paraformaldehyde for $1 \mathrm{~h}$ at room temperature, and washed three times for $5 \mathrm{~min}$ each time. Then, the roots were digested in $0.5 \%$ cellulase R-10 and $0.5 \%$ macerozyme $\mathrm{R}-10$ for $1 \mathrm{~h}$, and washed three times again. The root meristem was isolated and mounted on a glass slide. After being dyed with DAPI (4',6-diamidino-2phenylindole), the samples were pressed lightly, and their mitotic stages were recorded under an Olympus FluoView FV1000 confocal microscope.

\subsection{Treatment with DNA Replication Inhibitors and DNA Damage Reagents}

The seeds of rice Dongjin were germinated on $1 / 2$ MS medium for 10 days. The germinated seedlings that were selected for treatment tests grew well. Treatment reagents were $\mathrm{HU}(0,8$ and $16 \mathrm{mM})$, aphidicolin $(0,50,100$, and $150 \mu \mathrm{M})$, MMS $(0,272,544$, and $816 \mu \mathrm{M})$, and $\operatorname{MMC}(0,30,60,90$, and $150 \mu \mathrm{M})$. Samples treated at $0.5,1$, and 2 days were collected. Three seedlings were collected as one biological sample. Three independent biological replicates and three technical replicates were included in final data analysis.

\subsection{EdU Staining Analysis}

The 7-day-old seedlings were prepared for the EdU (ethynyl deoxyuridine) staining experiment [51]. The root tips were incubated in $50 \mu \mathrm{M}$ EdU solution for $2.5 \mathrm{~h}$, fixed in $4 \%$ paraformaldehyde and treated with Apollo reagent according to the cell-light EdU 
Apollo 488 in vitro imaging kit (RiboBio). The fluorescence was detected under a Leica SP8 confocal microscope and photographed.

\subsection{Comet Assay}

The nuclei of root apical meristem cells from 7-day-old rice seedlings were mixed with low melting-point agarose, and then the mixture was tiled on normal melting-point agarose on a glass slide. After the mixture was unwound and subjected to electrophoresis according to the protocol described previously [50], the mixture was dyed with PI (propidium iodide), and observed under a Leica SP8 confocal microscope. The data were analyzed using CometScore software (http://www.autocomet.com). DNA damage was calculated by averaging the values of the percentage of DNA in tails from more than 70 comets.

\subsection{Homology Modeling}

The sequence of OsMre11, OsRad50, OsNbs1, and their homologous proteins were downloaded from NCBI. Their 3D structures were modeled using the SWISS-MODEL server (http:/ / swissmodel.expasy.org/) [73,74]. The homology templates were 4yke.1.A, 5dac.1.A, and 3hue.1.A, respectively [75]. The PDB files of the modeled proteins were displayed and downloaded using Swiss-Pdb Viewer.

\subsection{BiFC Assay}

The full length ORFs (without stop codons) of OsMre11 (LOC_Os04g54340), OsRad50 (LOC_Os02g29464), and OsNbs1 (LOC_Os10g34580) were inserted into the $p$ CAMBIA$S P Y N E$ and $P C A M B I A-S P Y C E$ vectors, respectively, to make different plasmids. Then, the plasmids were injected into tobacco (Nicotiana benthamiana) leaf epidermis cells for BiFC (bimolecular fluorescence complementation) assay. Approximately $36 \mathrm{~h}$ later, fluorescence signals were observed. YN and YC stand for $p C A M B I A-S P Y N E$ and $p C A M B I A-S P Y C E$ empty vectors in the text respectively. The detailed procedure was performed according to Sparkes' method [76].

\subsection{Co-IP Analysis}

For Co-IP (co-immunoprecipitation) analysis, the CDS (without stop codons) of OsRad50 and OsNbs1 were obtained to construct the 35S::OsRad50-3 $\times$ Flag and 35S::OsNbs1-3 $\times$ Myc vectors, respectively. The 35S::OsMre11-GFP, 35S::OsRad50-3 $\times$ Flag, and 35S::OsNbs1-3 $\times$ Myc vectors were injected into tobacco leaf epidermis cells and cultivated for $36 \mathrm{~h}$. The proteins used for the Co-IP assay were incubated with anti-Myc and anti-Flag mouse antibodies, respectively. Immunoblotting was performed with anti-GFP, anti-Flag and anti-Myc rabbit antibodies, respectively. The detailed process was performed as described previously [77].

\subsection{RNA-Seq Assay}

The 7-day-old seedlings of WT and osmre11 were harvested. Three plants were used as one sample, and both of WT and the osmre11 contained two samples. Their whole RNA was extracted and sequenced by GENEWIZ Company. The steps of RNA extraction are briefly described below. The samples were lysed with Trizol reagent. RNA was extracted with chloroform and precipitated with isopropanol. In addition, $75 \%$ alcohol was used to clean the impurities, and finally RNA was dissolved with RNase-free water. Sequencing reads were mapped to the reference genome and transcriptome sequences (http://rice.plantbiology.msu.edu/ pub/data/Eukaryotic_Projects/o_sativa/annotation_dbs/pseudomolecules/version_7.0/). The model of NGS was Illumina HiSeq2000. The transcriptome sequencing experiment process includes RNA extraction, RNA sample quality detection, library construction, library purification, library detection, library quantification, sequencing cluster generation, and computer sequencing. The length we obtained was $150 \mathrm{bp}$, and the numbers of reads were $49,948,012,43,922,662,43,510,058$, and 52,841,196. Htseq software (V 0.6.1) was used for gene expression calculation, DESeq2 (V1.6.3) of Bioconductor software was used for 
gene difference analysis, and DEXSeq (V1.18.4) software was used for differential exon usage analysis. The threshold for significance was $p<0.05$. GO (Gene ontology) analysis was carried out by WEGO (Web Gene Ontology Annotation Plot; http:/ /wego.genomics. org.cn/cgi-bin/wego/index.pl). KEGG (Kyoto Encyclopedia of Genes and Genomes) was analyzed by the method described previously [78]. From KEGG correlation analysis results, homologous recombination and non-homologous end joining repair pathways were selected, and the related changed genes were displayed [78-80]. All the raw data of RNA-seq was uploaded in the GEO database of NCBI. The GEO series is GSE163616. Gene Expression Omnibus (https: / / www.ncbi.nlm.nih.gov/geo/query / acc.cgi?acc=GSE163616).

Supplementary Materials: The following are available online at https:/ /www.mdpi.com/1422-006 7/22/1/169/s1, Figure S1: Comparison of the amino acid sequences of OsMre11 and its homologs. Figure S2: Phylogenetic analysis of OsMre11 and other 11 homologs. Figure S3: Expression patterns of OsRad50 and OsNbs1 in rice. Figure S4: Relative expression level of OsMre11 responded to Aphidicolin and MMC in 10DAG seedlings. Figure S5: The three-dimensional structure of Mre11, Rad50, and Nbs1 in various species. Figure S6: BiFC assay shows the interaction relationships between OsMre11, OsRad50, and Os-Nbs1 in tobacco leaf epidermis cells. Figure S7: RNA-seq analysis of wild type and the mre11 mutant in rice. Table S1: Primers $\left(5^{\prime}\right.$ to $\left.3^{\prime}\right)$ used in the experiments.

Author Contributions: J.Z. designed the study plans, guided the whole study, and wrote and modified the paper. M.S. designed the study, carried out most experiments, analyzed data, wrote and revised the manuscript. Y.N., Y.C. and X.Z. contributed to acquisition and identification of the test materials. All authors have read and agreed to the published version of the manuscript.

Funding: This research was supported by the National Natural Science Foundation of China (31870303, 31670312).

Institutional Review Board Statement: Not applicable.

Informed Con sent Statement: Not applicable.

Data Availability Statement: The T-DNA inserted mutant mre11 was obtained from a RISD-DB Mutant Library (Rice T-DNA Insertion Sequence Database, http:/ / cbi.khu.ac.kr/RISD_DB.html).

Acknowledgments: We are very thankful to Lijia Qu (Peking University, China) for generously providing vectors of CRISPR/Cas9, and Jianguo Wu (Wuhan University, China) for the help in the protein-related experiments.

Conflicts of Interest: The authors declare no conflict of interest.

\section{References}

1. Waldminghaus, T.; Skarstad, K. The Escherichia coli SeqA protein. Plasmid 2009, 61, 141-150. [CrossRef] [PubMed]

2. Campbell, J.L.; Kleckner, N.E. coli oriC and the dnaA gene promoter are sequestered from dam methyltransferase following the passage of the chromosomal replication fork. Cell 1990, 62, 967-979. [CrossRef]

3. Fragkos, M.; Ganier, O.; Coulombe, P.; Mechali, M. DNA replication origin activation in space and time. Nat. Rev. Mol. Cell Biol. 2015, 16, 360-374. [CrossRef] [PubMed]

4. Nishitani, H.; Lygerou, Z. Control of DNA replication licensing in a cell cycle. Genes Cells 2002, 7, 523-534. [CrossRef]

5. Johnson, C.; Gali, V.K.; Takahashi, T.S.; Kubota, T. PCNA Retention on DNA into G2/M Phase Causes Genome Instability in Cells Lacking Elg1. Cell Rep. 2016, 16, 684-695. [CrossRef]

6. Knoll, A.; Fauser, F.; Puchta, H. DNA recombination in somatic plant cells: Mechanisms and evolutionary consequences. Chromosome Res. 2014, 22, 191-201. [CrossRef]

7. Rich, T.; Allen, R.L.; Wyllie, A.H. Defying death after DNA damage. Nature 2000, 407, 777-783. [CrossRef]

8. Puchta, H. The repair of double-strand breaks in plants: Mechanisms and consequences for genome evolution. J. Exp. Bot. 2005, 56, 1-14. [CrossRef]

9. Lukas, J.; Lukas, C. Molecular biology. Shielding broken DNA for a quick fix. Science 2013, 339, 652-653. [CrossRef]

10. Hopfner, K.P. DNA Double-Strand Breaks Come into Focus. Cell 2009, 139, 25-27. [CrossRef]

11. Czornak, K.; Chughtai, S.; Chrzanowska, K.H. Mystery of DNA repair: The role of the MRN complex and ATM kinase in DNA damage repair. J. Appl. Genet. 2008, 49, 383-396. [CrossRef] [PubMed]

12. Amiard, S.; Charbonnel, C.; Allain, E.; Depeiges, A.; White, C.I.; Gallego, M.E. Distinct Roles of the ATR Kinase and the Mre11Rad50-Nbs1 Complex in the Maintenance of Chromosomal Stability in Arabidopsis. Plant Cell 2010, 22, 3020-3033. [CrossRef] [PubMed] 
13. Bai, Y.T.; Wang, W.B.; Li, S.Y.; Zhan, J.; Li, H.X.; Zhao, M.M.; Zhou, X.A.; Li, S.W.; Li, X.M.; Huo, Y.F.; et al. C1QBP Promotes Homologous Recombination by Stabilizing MRE11 and Controlling the Assembly and Activation of MRE11/RAD50/NBS1 Complex. Mol. Cell 2019, 75, 1299-1314.e6. [CrossRef] [PubMed]

14. Aravind, L.; Walker, D.R.; Koonin, E.V. Conserved domains in DNA repair proteins and evolution of repair systems. Nucleic Acids Res. 1999, 27, 1223-1242. [CrossRef]

15. Paull, T.T.; Gellert, M. Nbs1 potentiates ATP-driven DNA unwinding and endonuclease cleavage by the Mre11/Rad50 complex. Genes Dev. 1999, 13, 1276-1288. [CrossRef]

16. Paull, T.T.; Gellert, M. The $3^{\prime}$ to $5^{\prime}$ exonuclease activity of Mre 11 facilitates repair of DNA double-strand breaks. Mol. Cell 1998, 1, 969-979. [CrossRef]

17. Paull, T.T. 20 Years of Mre11 Biology: No End in Sight. Mol. Cell 2018, 71, 419-427. [CrossRef]

18. Hopfner, K.P.; Craig, L.; Moncalian, G.; Zinkel, R.A.; Usui, T.; Owen BA, L.; Karcher, A.; Henderson, B.; Bodmer, J.L.; McMurray, C.T.; et al. The Rad50 zinc-hook is a structure joining Mre11 complexes in DNA recombination and repair. Nature 2002, 418, 562-566. [CrossRef]

19. Tauchi, H.; Kobayashi, J.; Morishima, K.; van Gent, D.C.; Shiraishi, T.; Verkaik, N.S.; vanHeems, D.; Ito, E.; Nakamura, A.; Sonodo, E.; et al. Nbs1 is essential for DNA repair by homologous recombination in higher vertebrate cells. Nature 2002, 420, 93-98. [CrossRef]

20. Falck, J.; Coates, J.; Jackson, S.P. Conserved modes of recruitment of ATM, ATR and DNA-PKcs to sites of DNA damage. Nature 2005, 434, 605-611. [CrossRef]

21. Lee, J.H.; Paull, T.T. ATM activation by DNA double-strand breaks through the Mre11-Rad50-Nbs1 complex. Science 2005, 308, 551-554. [CrossRef] [PubMed]

22. Wang, C.; Higgins, J.D.; He, Y.; Lu, P.; Zhang, D.; Liang, W. Resolvase OsGEN1 Mediates DNA Repair by Homologous Recombination. Plant Physiol. 2017, 173, 1316-1329. [CrossRef] [PubMed]

23. Wang, W.B.; Daley, J.M.; Kwon, Y.; Krasner, D.S.; Sung, P. Plasticity of the Mre11-Rad50-Xrs2-Sae2 nuclease ensemble in the processing of DNA-bound obstacles. Genes Dev. 2017, 31, 2331-2336. [CrossRef] [PubMed]

24. Cannavo, E.; Cejka, P. Sae2 promotes dsDNA endonuclease activity within Mre11-Rad50-Xrs2 to resect DNA breaks. Nature 2014, 514, 122-125. [CrossRef] [PubMed]

25. Reginato, G.; Cannavo, E.; Cejka, P. Physiological protein blocks direct the Mre11-Rad50-Xrs2 and Sae2 nuclease complex to initiate DNA end resection. Genes Dev. 2017, 31, 2325-2330. [CrossRef] [PubMed]

26. Lavin, M.F.; Birrell, G.; Chen, P.; Kozlov, S.; Scott, S.; Gueven, N. ATM signaling and genomic stability in response to DNA damage. Mutat. Res. 2005, 569, 123-132. [CrossRef]

27. Mimitou, E.P.; Symington, L.S. DNA end resection: Many nucleases make light work. DNA Repair 2009, 8, 983-995. [CrossRef]

28. Gallego, M.E.; Jeanneau, M.; Granier, F.; Bouchez, D.; Bechtold, N.; White, C.I. Disruption of the Arabidopsis RAD50 gene leads to plant sterility and MMS sensitivity. Plant J. 2001, 25, 31-41.

29. Waterworth, W.M.; Altun, C.; Armstrong, S.J.; Roberts, N.; Dean, P.J.; Young, K.; Weil, C.F.; Bray, C.M.; West, C.E. NBS1 is involved in DNA repair and plays a synergistic role with ATM in mediating meiotic homologous recombination in plants. Plant J. 2007, 52, 41-52. [CrossRef]

30. Ajimura, M.; Leem, S.H.; Ogawa, H. Identification of New Genes Required for Meiotic Recombination in SaccharomycesCerevisiae. Genetics 1993, 133, 51-66.

31. Tavassoli, M.; Shayeghi, M.; Nasim, A.; Watts, F.Z. Cloning and Characterization of the Schizosaccharomyces-Pombe Rad32 Gene-A Gene Required for Repair of Double-Strand Breaks and Recombination. Nucleic Acids Res. 1995, 23, 383-388. [CrossRef] [PubMed]

32. Chin, G.M.; Villeneuve, A.M. C-elegans mre-11 is required for meiotic recombination and DNA repair but is dispensable for the meiotic G(2) DNA damage checkpoint. Genes Dev. 2001, 15, 522-534. [CrossRef] [PubMed]

33. Buis, J.; Wu, Y.P.; Deng, Y.B.; Leddon, J.; Westfield, G.; Eckersdorff, M.; Sekiguchi, J.M.; Chang, S.; Ferguson, D.O. Mre11 nuclease activity has essential roles in DNA repair and genomic stability distinct from ATM activation. Cell 2008, 135, 85-96. [CrossRef] [PubMed]

34. Carney, J.P.; Maser, R.S.; Olivares, H.; Davis, E.M.; Le Beau, M.; Yates, J.R.; Hays, L.; Morgan, W.F.; Petrini, J.H. The hMre11/hRad50 protein complex and Nijmegen breakage syndrome: Linkage of double-strand break repair to the cellular DNA damage response. Cell 1998, 93, 477-486. [CrossRef]

35. Ji, J.H.; Tang, D.; Wang, M.; Li, Y.F.; Zhang, L.; Wang, K.J.; Li, M.; Cheng, Z.K. MRE11 is required for homologous synapsis and DSB processing in rice meiosis. Chromosoma 2013, 122, 363-376. [CrossRef]

36. Maser, R.S.; Zinkel, R.; Petrini JH, J. An alternative mode of translation permits production of a variant NBS1 protein from the common Nijmegen breakage syndrome allele. Nat. Genet. 2001, 27, 417-421. [CrossRef]

37. Hayashi, K.; Hasegawa, J.; Matsunaga, S. The boundary of the meristematic and elongation zones in roots: Endoreduplication precedes rapid cell expansion. Sci. Rep. 2013, 3, 2723. [CrossRef]

38. Ostling, O.; Johanson, K.J. Microelectrophoretic Study of Radiation-Induced DNA Damages in Individual Mammalian-Cells. Biochem. Biophys. Res. Commun. 1984, 123, 291-298. [CrossRef]

39. Gobbini, E.; Cassani, C.; Villa, M.; Bonetti, D.; Longhese, M.P. Functions and regulation of the MRX complex at DNA double-strand breaks. Microb. Cell 2016, 3, 329-337. [CrossRef] 
40. Lu, H.M.; Shamanna, R.A.; Keijzers, G.; Anand, R.; Rasmussen, L.J.; Cejka, P.; Croteau, D.L.; Bohr, V.A. RECQL4 Promotes DNA End Resection in Repair of DNA Double-Strand Breaks. Cell Rep. 2016, 16, 161-173. [CrossRef]

41. Wright, W.D.; Shah, S.S.; Heyer, W.D. Homologous recombination and the repair of DNA double-strand breaks. J. Biol. Chem. 2018, 293, 10524-10535. [CrossRef] [PubMed]

42. Jasin, M.; Rothstein, R. Repair of strand breaks by homologous recombination. Cold Spring Harb. Perspect. Biol. 2013, 5, a012740. [CrossRef] [PubMed]

43. Chang, H.H.; Pannunzio, N.R.; Adachi, N.; Lieber, M.R. Non-homologous DNA end joining and alternative pathways to double-strand break repair. Nat. Rev. Mol. Cell Biol. 2017, 18, 495-506. [CrossRef] [PubMed]

44. Pannunzio, N.R.; Watanabe, G.; Lieber, M.R. Nonhomologous DNA end-joining for repair of DNA double-strand breaks. J. Biol. Chem. 2018, 293, 10512-10523. [CrossRef] [PubMed]

45. Furuse, M.; Nagase, Y.; Tsubouchi, H.; Murakami-Murofushi, K.; Shibata, T.; Ohta, K. Distinct roles of two separable in vitro activities of yeast Mre11 in mitotic and meiotic recombination. EMBO J. 1998, 17, 6412-6425. [CrossRef] [PubMed]

46. Aravind, L.; Koonin, E.V. Phosphoesterase domains associated with DNA polymerases of diverse origins. Nucleic Acids Res. 1998, 26, 3746-3752. [CrossRef] [PubMed]

47. Stewart, G.S.; Maser, R.S.; Stankovic, T.; Bressan, D.A.; Kaplan, M.I.; Jaspers NG, J.; Raams, A.; Byrd, P.J.; Petrini JH, J.; Taylor AM, $\mathrm{R}$. The DNA double-strand break repair gene hMRE11 is mutated in individuals with an ataxia-telangiectasia-like disorder. Cell 1999, 99, 577-587. [CrossRef]

48. Schiller, C.B.; Lammens, K.; Guerini, I.; Coordes, B.; Feldmann, H.; Schlauderer, F.; Mockel, C.; Schele, A.; Strasser, K.; Jackson, S.P.; et al. Structure of Mre11-Nbs1 complex yields insights into ataxia-telangiectasia-like disease mutations and DNA damage signaling. Nat. Struct. Mol. Biol. 2012, 19, 693. [CrossRef]

49. Bundock, P.; Hooykaas, P. Severe developmental defects, hypersensitivity to DNA-damaging agents, and lengthened telomeres in Arabidopsis MRE11 mutants. Plant Cell 2002, 14, 2451-2462. [CrossRef]

50. Li, G.; Zou, W.X.; Jian, L.F.; Qian, J.; Deng, Y.T.; Zhao, J. Non-SMC elements 1 and 3 are required for early embryo and seedling development in Arabidopsis. J. Exp. Bot. 2017, 68, 1039-1054. [CrossRef]

51. Qian, J.; Chen, Y.Y.; Hu, Y.; Deng, Y.T.; Liu, Y.; Li, G.; Zou, W.X.; Zhao, J. Arabidopsis replication factor C4 is critical for DNA replication during the mitotic cell cycle. Plant J. 2018, 94, 288-303. [CrossRef] [PubMed]

52. Šamanić, I.; Cvitanić, R.; Simunić, J.; Puizina, J. Arabidopsis thaliana MRE11 is essential for activation of cell cycle arrest, transcriptional regulation and DNA repair upon the induction of double-stranded DNA breaks. Plant Biol. 2016, 18, 681-694. [CrossRef] [PubMed]

53. Niu, M.; Wang, Y.H.; Wang, C.M.; Lyu, J.; Wang, Y.L.; Dong, H.; Long, W.H.; Wang, D.; Kong, W.Y.; Wang, L.W.; et al. ALR encoding dCMP deaminase is critical for DNA damage repair, cell cycle progression and plant development in rice. J. Exp. Bot. 2017, 68, 5773-5786. [CrossRef] [PubMed]

54. Kalhorzadeh, P.; Hu, Z.B.; Cools, T.; Amiard, S.; Willing, E.M.; De Winne, N.; Gevaert, K.; De Jaeger, G.; Schneeberger, K.; White, C.I.; et al. Arabidopsis thaliana RNase H2 Deficiency Counteracts the Needs for the WEE1 Checkpoint Kinase but Triggers Genome Instability. Plant Cell 2014, 26, 3680-3692. [CrossRef]

55. Vesela, E.; Chroma, K.; Turi, Z.; Mistrik, M. Common Chemical Inductors of Replication Stress: Focus on Cell-Based Studies. Biomolecules 2017, 7, 19. [CrossRef]

56. Bleuyard, J.Y.; Gallego, M.E.; White, C.I. Meiotic defects in the Arabidopsis rad50 mutant point to conservation of the MRX complex function in early stages of meiotic recombination. Chromosoma 2004, 113, 197-203. [CrossRef]

57. Puizina, J.; Siroky, J.; Mokros, P.; Schweizer, D.; Riha, K. Mre11 deficiency in Arabidopsis is associated with chromosomal instability in somatic cells and Spo11-dependent genome fragmentation during meiosis. Plant Cell 2004, 6, 1968-1978. [CrossRef]

58. Lobachev, K.; Vitriol, E.; Stemple, J.; Resnick, M.A.; Bloom, K. Chromosome fragmentation after induction of a double-strand break is an active process prevented by the RMX repair complex. Curr. Biol. 2004, 14, 2107-2112. [CrossRef]

59. Kaye, J.A.; Melo, J.A.; Cheung, S.K.; Vaze, M.B.; Haber, J.E.; Toczyski, D.P. DNA breaks promote genomic instability by impeding proper chromosome segregation. Curr. Biol. 2004, 14, 2096-2106. [CrossRef]

60. Wiltzius, J.J.; Hohl, M.; Fleming, J.C.; Petrini, J.H. The Rad50 hook domain is a critical determinant of Mre11 complex functions. Nat. Struct. Mol. Biol. 2005, 12, 403-407. [CrossRef]

61. Reuven, N.; Adler, J.; Broennimann, K.; Myers, N.; Shaul, Y. Recruitment of DNA Repair MRN Complex by Intrinsically Disordered Protein Domain Fused to Cas9 Improves Efficiency of CRISPR-Mediated Genome Editing. Biomolecules 2019, 9, 584. [CrossRef] [PubMed]

62. Xu, P.L.; Yuan, D.K.; Liu, M.; Li, C.X.; Liu, Y.Y.; Zhang, S.C.; Yao, N.; Yang, C.W. AtMMS21, an SMC5/6 Complex Subunit, Is Involved in Stem Cell Niche Maintenance and DNA Damage Responses in Arabidopsis Roots. Plant Physiol. 2013, 161, 1755-1768. [CrossRef] [PubMed]

63. Wang, Y.X.; Xiao, R.; Wang, H.F.; Cheng, Z.H.; Li, W.X.; Zhu, G.F.; Wang, Y.; Ma, H. The Arabidopsis RAD51 paralogs RAD51B, RAD51D and XRCC2 play partially redundant roles in somatic DNA repair and gene regulation. New Phytol. 2014, 201, 292-304. [CrossRef] [PubMed]

64. Da Ines, O.; Degroote, F.; Amiard, S.; Goubely, C.; Gallego, M.E.; White, C.I. Effects of XRCC2 and RAD51B mutations on somatic and meiotic recombination in Arabidopsis thaliana. Plant J. 2013, 74, 959-970. [CrossRef] 
65. Xu, Z.; Zhang, J.; Xu, M.; Ji, W.; Yu, M.; Tao, Y.; Gong, Z.; Gu, M.; Yu, H. Rice RAD51 paralogs play essential roles in somatic homologous recombination for DNA repair. Plant J. 2018, 95, 282-295. [CrossRef]

66. Peng, X.J.; Liu, S.J.; Bao, C.M.; Liu, Y.Z.; Xie, H.W.; Cai, Y.H.; Li, B.M.; Hang, H.Y.; Ding, X. Regulation of ATRIP protein abundance by RAD9 in the DNA damage repair pathway. Cell Mol. Biol. 2015, 61, 31-36.

67. Zhao, B.; Watanabe, G.; Morten, M.J.; Reid, D.A.; Rothenberg, E.; Lieber, M.R. The essential elements for the noncovalent association of two DNA ends during NHEJ synapsis. Nat. Commun. 2019, 10, 3588. [CrossRef]

68. Samanić, I.; Simunić, J.; Riha, K.; Puizina, J. Evidence for distinct functions of MRE11 in Arabidopsis meiosis. PLoS ONE 2013, 8, e78760.

69. Miao, J.; Guo, D.S.; Zhang, J.Z.; Huang, Q.P.; Qin, G.J.; Zhang, X.; Wan, J.M.; Gu, H.Y.; Qu, L.J. Targeted mutagenesis in rice using CRISPR-Cas system. Cell Res. 2013, 23, 1233-1236. [CrossRef]

70. Zhong, H.; Simons, J.W. Direct comparison of GAPDH, beta-actin, cyclophilin, and 28S rRNA as internal standards for quantifying RNA levels under hypoxia. Biochem. Biophys. Res. Commun. 1999, 259, 523-526. [CrossRef]

71. Jefferson, R.A.; Kavanagh, T.A.; Bevan, M.W. Gus Fusions-Beta-Glucuronidase as a Sensitive and Versatile Gene Fusion Marker in Higher-Plants. EMBO J. 1987, 6, 3901-3907. [CrossRef] [PubMed]

72. Zhou, S.L.; Jiang, W.; Long, F.; Cheng, S.F.; Yang, W.J.; Zhao, Y.; Zhou, D.X. Rice Homeodomain Protein WOX11 Recruits a Histone Acetyltransferase Complex to Establish Programs of Cell Proliferation of Crown Root Meristem. Plant Cell 2017, 29, $1088-1104$. [CrossRef]

73. Guex, N.; Peitsch, M.C.; Schwede, T. Automated comparative protein structure modeling with SWISS-MODEL and SwissPdbViewer: A historical perspective. Electrophoresis 2009, 30, S162-S173. [CrossRef] [PubMed]

74. Biasini, M.; Bienert, S.; Waterhouse, A.; Arnold, K.; Studer, G.; Schmidt, T.; Kiefer, F.; Cassarino, T.G.; Bertoni, M.; Bordoli, L.; et al. SWISS-MODEL: Modelling protein tertiary and quaternary structure using evolutionary information. Nucleic Acids Res. 2014, 42, W252-W258. [CrossRef] [PubMed]

75. Seifert, F.U.; Lammens, K.; Hopfner, K.P. Structure of the catalytic domain of Mre11 from Chaetomium thermophilum. Acta Crystallogr. Sect. F-Struct. Biol. Commun. 2015, 71, 752-757. [CrossRef] [PubMed]

76. Sparkes, I.A.; Runions, J.; Kearns, A.; Hawes, C. Rapid, transient expression of fluorescent fusion proteins in tobacco plants and generation of stably transformed plants. Nat. Protoc. 2006, 1, 2019-2025. [CrossRef]

77. Deng, Y.T.; Zou, W.X.; Li, G.; Zhao, J. TRANSLOCASE OF THE INNER MEMBRANE9 and 10 Are Essential for Maintaining Mitochondrial Function during Early Embryo Cell and Endosperm Free Nucleus Divisions in Arabidopsis. Plant Physiol. 2014, 166, 853-868. [CrossRef]

78. Kanehisa, M.; Araki, M.; Goto, S.; Hattori, M.; Hirakawa, M.; Itoh, M.; Katayama, T.; Kawashima, S.; Okuda, S.; Tokimatsu, T.; et al. KEGG for linking genomes to life and the environment. Nucleic Acids Res. 2008, 36, D480-D484. [CrossRef]

79. Symington, L.S. Role of RAD52 epistasis group genes in homologous recombination and double-strand break repair. Microbiol. Mol. Biol. Rev. 2002, 66, 630-670. [CrossRef]

80. Roy, S.; Choudhury, S.R.; Sengupta, D.N.; Das, K.P. Involvement of AtPollambda in the repair of high salt- and DNA cross-linking agent-induced double strand breaks in Arabidopsis. Plant Physiol. 2013, 162, 1195-1210. [CrossRef] 